\title{
Bifunctional Binols: Chiral 3,3'-Bis(aminomethyl)-1,1'-bi-2-napththols (Binolams) in Asymmetric Catalysis
}

\author{
Carmen Nájera $^{[a]}$ José M. Sansano $^{[a] *}$ and José M. Saá ${ }^{[b]}$
}

Dedicated to Prof. Andreas Pfaltz on the occasion of his $60^{\text {th }}$ birthday

Keywords: (Asymmetric catalysis/ Binolam / organocatalysis / chiral complexes /bifunctional catalysts)

\begin{abstract}
3,3'-Bis(dialkylaminomethyl)-1,1'binaphth-2-ols (Binolams) have emerged during the last five years as very efficient chiral ligands in many enantioselective processes. Enantiomerically pure Binolams are easily accessible by means of a variety of methods, the most widely used being the so-called chiral Binol route. In most cases, Binolam-metal complexes behave as bifunctional catalysts i.e., they are characterized by their dual action over the reagents, as they can activate both the nucleophilic and the electrophilic species involved in the reaction.
\end{abstract}

The most successful transformations carried out with these type of complexes include: the cyanation of aldehydes and ketones, the enantioselective nucleophilic additions of enolate derivatives and organometallic compounds to $\mathrm{C}=\mathrm{O}$ or $\mathrm{C}=\mathrm{N}$ double bonds. As a final bonus, the basic nature of these ligands allows its recovery in high yield in numerous transformations.

(C) WILEY-VCH Verlag GmbH \& Co. KGaA, 69451 Weinheim, Germany, 2007)

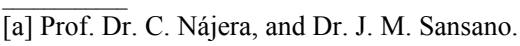

Departamento de Química Orgánica e Instituto de Síntesis Orgánica (ISO), Facultad de Ciencias, Universidad de Alicante, Apartado 99, 03080 Alicante (Spain)

Fax: Int. Code + (34)965903549

e-mail: cnajera@ua.es,jmsansano@ua.es.

[b] Prof. Dr. J. M. Saá.

Departament de Química, Universitat de les Illes Balears, 07122 Palma de Mallorca (Spain)

Fax: Code +(34) 971173426

E-mail: jmsaa@uib.es

\section{Introduction}

The widespread demand for enantiomerically pure compounds ultimately comes from the central role that enantiomer recognition and differential reactivity of enantiomers play in biological activity. There are many examples of pharmaceutical drugs, agrochemicals, flavors, and fragances, where the desired property is related to their absolute configuration. ${ }^{[1]}$ This pervasive request for chiral compounds has stimulated intensive research to develop improved methods for accessing them. ${ }^{[2]}$ Non-enzymatic strategies towards the preparation of enantiomerically pure compounds fall into the following three main categories: a) resolution of a racemic mixture, either spontaneous or with the aid of an enantiopure reagent; b) structural modification of an enantiomerically pure substrate (in most cases of natural origin), which undergo highly diastereoselective transformations; and c) conversion of an achiral precursor into a chiral product (asymmetric synthesis) performed using chiral auxiliaries, reagents, or catalysts (asymmetric catalysis).

The design of new catalysts for common, and not so common, reactions is the leit motiv of asymmetric catalysis, the inception of which usually involves the design of feasible ligands. The invention of the earliest ligands for asymmetric hydrogenations catalyzed by transition metal complexes occurred in the early 1970 s, and is nowadays in continuous expansion. ${ }^{[3]}$ In recognition of the achievements obtained by the so called artificial enzymes, Knowles, Noyori, and Sharpless shared the 2001 Nobel Prize in chemistry. Since those early days, a myriad of chiral catalysts have been mainly employed in the generation of stereogenic centers through $\mathrm{C}-\mathrm{O}, \mathrm{C}-\mathrm{N}$, and $\mathrm{C}-\mathrm{C}$ bond forming reactions. ${ }^{[3]}$ The chiral ligand is a crucial part in these active catalysts. ${ }^{[4]}$ Not only should it increase the reactivity but it should also provide a kinetic bias in such a way that one of the two possible enantiomeric products is formed preferentially. The design of suitable chiral ligands for a particular application remains, however, a formidable task. The complexity of most catalytic processes precludes a purely rational approach based on mechanistic and structural criteria. Therefore, most new chiral catalysts are still found empirically, for which purpose a combination of chance, intuition, and systematic screening, all playing important roles, is required. 
Bifunctional catalysts ${ }^{[5]}$ merit an especial comment as their dual function (activation of both nucleophile and electrophile in a ternary complex) leads to a further lowering of the transition structure and thus to further acceleration. We have devoted our efforts in recent years to explore the use of bifunctional Binol derivatives in the asymmetric catalysis area. Particularly, $\mathrm{C}_{2}-$ symmetric $^{[6}$ ] 3,3'-bis(dialkylamino methyl)-1,1'binaphth-2-ols (Binolam ligands) of general structure I (Figure 1a), and, in less extension, the $\mathrm{C}_{1}$-symmetric, single armed ligands II (Figure 1b), emerged to our sight as highly valuable scaffolds for the possible generation of bifunctional chiral Lewis acids and/or organocatalysts. Moreover, according to the X-ray diffraction structure of 3,3'-bis(diethylaminomethyl)-1,1'binaphth-2-ol, Binolams appear to be ideally suited to form octahedral complexes with appropriate metals (Figure 1c). ${ }^{7}$ Unlike unsubstituted Binol ligands, ${ }^{[8,9]}$ the key feature of the resulting bifunctional Lewis acids is the different electronic domains present in the metal cation and in the aminomethyl-arms, which facilitate their dual action as shown in III, i.e. the metal cation acting as a chiral Lewis acid in activating the electrophilic species, whilst the aminomethyl-arm facilitates the suitable approach of the nucleophile (Figure 1d).

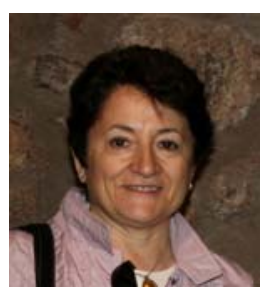

Carmen Nájera obtained her B.Sc. at the University of Zaragoza in 1973 and her Ph.D. at the University of Oviedo She performed postdoctoral work at the ETH (Zurich) with D. Seebach, at the Dyson Perrins Laboratory (Oxford) with J. E. Baldwin,at Harvard University with E. J. Corey, and at Uppsala University withJ.-E. Bäckvall. She was promoted to Associate Professor in 1985 at the University of Oviedo and Full Professor in 1993 at the University of Alicante. She was awarded with the "2006 Janssen Cilag Organic Chemistry Prize" from the Spanish Royal Chemical Society of Chemistry and the "2006 Rosalind Franklin International Lectureship" from the English Royal Society.

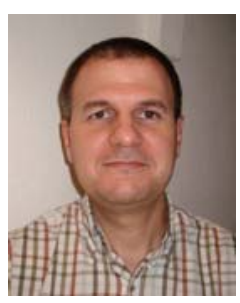

José Miguel Sansano studied chemistry at the University of Alicante, where he obtained his B.Sc. and Ph.D. degrees in 1988 and 1994, respectively. After spending a two-year postdoctoral stay at the University of Leeds (U.K.) with Prof. R. Grigg, he joined the University of Alicante in 1996, where he was appointed Associate Professor in 2001.

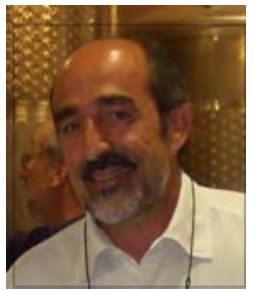

José M. Saá was born in Lugo (Spain) in 1948, studied Chemistry at the University of Santiago de Compostela, and did his PhD under the direction of Prof. Ignacio Ribas and Luis Castedo. After postdoctoral research with Prof. M.P. Cava at the University of Pennsylvania (Philadelphia) he first joined the faculty of the University of Santiago de Compostela (Spain) in 1978, and then moved to the University of the Balearic Islands (UIB) in 1982, where he is full professor since 1986. 
<smiles>[R12]NCc1cc2ccccc2c(-c2c(CN[R12])cc3ccccc3c2O)c1O</smiles>

$(R)-\mathbf{I}$<smiles>[R12]NCc1cc2ccccc2c(-c2c(O)ccc3ccccc23)c1O</smiles>

(R)-II

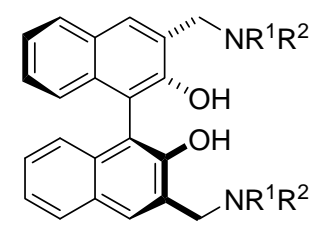

(S)-I

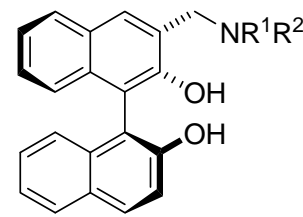

(S)-II a)

b)

c)

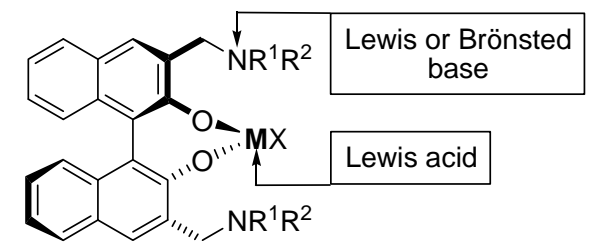

(R)-III

Figure 1.

Several applications of Binolams I or II other than in asymmetric synthesis have been reported in the areas of host-guest complexation and molecular recognition, ${ }^{[10,11,12]}$ as well as in the development of macromolecular architectures, ${ }^{[13]}$ and in the construction of artificial enzymes and membranes. ${ }^{[14]}$ In addition, two important properties of these structures I have to be highlighted: a) Binolams are potent DNA combining agents, a property that makes them promising molecules for anticancer therapies ${ }^{[15,16]}$ and; b) the fluorescent properties of Binolams are highly useful for chiral recognition. ${ }^{[16]}$

Due to our interest in asymmetric catalysis, we will center the discussion of this review on two issues. Firstly, we will examine the preparation of Binolams I and secondly, the focus will be upon the results achieved in asymmetric catalysis with Binolams and derivatives thereof. In particular, we will examine chiral 3dialkylaminomethyl-1,1'-binaphth-2-ols I either as organocatalysts, or as metal catalysts (typically generated in situ by reaction with the appropriate metal derivative), capable of mediating enantioselective processes where $\mathrm{C}-\mathrm{O}$ and $\mathrm{C}-\mathrm{C}$ bond-forming reactions occur.

\section{Synthesis of chiral Binolam ligands of type $I$ and} II

The synthesis of Binolam ligands I and derivatives thereof, have been inspired, in general on the numerous strategies developed for the preparation of the chiral Binol-type systems. ${ }^{[8,9]}$ In fact, the most useful methodologies to obtain them involve either: a) the separation of diastereomeric mixtures of appropriate Binol derivatives mediated by chiral $\alpha$-amino acid surrogates; $b$ ) dynamic kinetic transformations (DYKAT); c) a transition-metal catalyzed enantioselective, or diastereoselective $\mathrm{Csp}^{2}-\mathrm{Csp}^{2}$ coupling between two identical or two different binaphth-2-ol units; and d) the appropriate functionalization of enantiomerically enriched Binols.

Cram and coworkers were the first to report the optical resolution of Binol acid rac-2, itself synthesized by a standard copper-catalyzed $\mathrm{Csp}^{2}-\mathrm{Csp}^{2}$ homocoupling of the methyl ester $\mathbf{1}$ followed by subsequent hydrolysis, ${ }^{[17]}$ by means of L-leucine methyl ester, thereby leading to enantiomerically pure compounds $\left(R_{\mathrm{a}}\right)-2$ and $\left(S_{\mathrm{a}}\right)-2$ (Scheme 1). ${ }^{[10]}$ However, this tedious separation sequences requires long reaction times (a week), and its efficiency is somewhat poor (the final yields achieved of the titled compounds 2 were around to $35 \%$ ). The enantiomerically enriched dicarboxylic acids 2 thereby obtained are the direct precursors of Binolams I through a sequence involving the formation of the corresponding bis-acyl chlorides followed by amide formation and complete reduction of the amide carbonyl group using $\mathrm{LiAlH}_{4}$ under refluxing THF. A large number of enantiopure Binolams prepared according to this protocol have been described. ${ }^{[7]}$

Photolysis of ortho-substituted Binols $3(\mathrm{X}=\mathrm{OH})$, Binolams 4 $\left(\mathrm{X}=\mathrm{NR}_{2}\right)$, or of the corresponding ammonium salts $5\left(\mathrm{X}=\mathrm{NR}_{3}{ }^{+}\right)$, gives rise to reactive ortho-quinone methides which can be quenched by available nucleophiles. Freccero et al. have recently reported a highly efficient DYKAT process ${ }^{18}$ when photolysis of racemic 3,4 or 5 was carried out in the presence of enantiomerically pure proline tert-butyl ester $\mathbf{6}$, thereby giving rise to diastereomerically enriched bisproline 8 ( $>99$ de after separation). A second photochemically-induced transformation, carried out upon enantiomerically enriched $\mathbf{8}$ in the presence of secondary amines, yieded enantiomerically enriched $(>99 \%$ ee $)$ Binolams I (Scheme 1). ${ }^{[14]}$

On the other hand, copper-catalyzed coupling of enantiomerically pure naphthol carboxamide $\mathbf{9}$ took place diastereoselectively thereby leading to $\mathbf{1 0}(66 \%$ de) (Scheme 1). Fortunately, chromatographic purification allowed to isolate compound 10 in $97 \%$ de and $65 \%$ yield, which on subsequent hydrolysis afforded the dicarboxylic acid $\left(R_{\mathrm{a}}\right)-2$ in $97 \%$ ee, and, eventually, to the desired Binolams $\mathbf{I}^{[19]}$

The design of a versatile catalytic system, able to perform an enantioselective $\mathrm{Csp}^{2}-\mathrm{Csp}^{2}$ coupling between two identical or different binapht-2-ol units, has revealed to be a difficult task. A number of diamines ( $10 \mathrm{~mol} \%$ loadings) have been evaluated in the the enantioselective, copper-catalyzed homo-coupling of $\mathbf{1}$ the most efficient ligand being $(S, S)$-1,5-diaza-cis-decalin 12 which led to compound $\left(R_{\mathrm{a}}\right) \mathbf{- 1 1}$ in $91-93 \%$ ee (Scheme 2). ${ }^{[15,20]}$ Chiral $(S)-\alpha-$ methylbenzylamine 15 afforded only a $43 \%$ ee of product $\left(S_{\mathrm{a}}\right)-2,{ }^{[21]}$ 
but the complex formed by diamine $\mathbf{1 4}$ and copper(II) salts gave better enantioselections than other different ligands such as $(-)$ sparteine $13^{[22]}$ or the diamine derived from $(1 R)-(+)$-camphor $\mathbf{1 6}^{[23]}$ (Scheme 2). The catalytic complexes 12-CuX have been also tested in the synthesis of chiral binaphthyl polymers using this type of oxidative coupling or by a domino reaction including a GlaserHay coupling as terminating step. ${ }^{[20 \mathrm{a}]}$

The fourth synthetic plan calls for the direct functionalization of chiral enantiomerically pure $\left(R_{\mathrm{a}}\right)$ - or $\left(S_{\mathrm{a}}\right)$-Binol 17 , or of their bis$O$-methoxymethylated derivatives $\mathbf{1 8}$. Thus, selective double deprotonation at C3 and C3' positions followed with quenching with carbon dioxide or DMF, gives rise to enantiomerically pure dicarboxylic acid $2,{ }^{[24]}$ or dicarbaldehyde $19,{ }^{[25]}$ respectively, in very good yields and without loss of enantiomeric purity (Scheme 3). Subsequent functional group transformations upon the reactive formyl groups (reductive amination), or the easily available dihalides derivatives 20 ( $\mathrm{S}_{\mathrm{n}} 2$ displacement), led to enantiomerically pure Binolams I. Dicarboxylic acid $\mathbf{2}$ is also an appropriate starting point for the synthesis of $N, N$-disubstituted Binolams I. However, the reductive amination route of dicarbaldehyde $\mathbf{1 9}$ is desirable for the preparation of $\mathrm{N}$-monosubstituted Binolams. The use of bishalomethylarenes $\mathbf{2 0}$ is strongly recommended when a bistetraalkylammonium salt derived from Binolams $\mathbf{I}$ is required. On the other hand, direct functionalization of enantiomerically pure Binol by recourse to a Mannich reaction with $N$-hydroxymethyl dialkylamines at $110{ }^{\circ} \mathrm{C}$ under pressure $(25-30 \mathrm{psi})$ furnished a mixture of C3-monosubstituted Binolam II (30\% yield) and Binolam I ( $55 \%$ yield, $75 \%$ ee). Final recrystallization led to Binolam I in $37 \%$ yield and $>99 \% e e^{[26]}$ (Scheme 3). A further attempt at the direct functionalization of enantiopure Binol is based on the anionic Fries rearrangement underwent by dicarbamate $\left(R_{\mathrm{a}}\right)$ 21, on treatment with $s$-BuLi/TMEDA at very low temperature. The resulting diamide $\left(R_{\mathrm{a}}\right)$-22, obtained in moderate to good chemical yields, was eventually reduced with $\mathrm{LiAlH}_{4}$ thereby giving rise to the titled Binolams I with excellent $e e^{\prime}$ 's (Scheme $3) .{ }^{[27]}$ Partially hydrogenated Binolams are easily available by means of direct Mannich reaction upon the corresponding $\mathrm{H}_{8-}$ Binols. Actually, $\mathrm{H}_{8}$-Binolams are mildly obtained from commercially available $\mathrm{H}_{8}$-Binol and a mixture of formaldehyde/dialkylamine or, instead, by following analogous routes to those described for the titled Binolam ligands-type I. $^{[28,29]}$

In summary, taking together the advantages and disadvantages of the above-mentioned protocols for accessing enantiopure Binolams, it is safe to conclude that those based on the direct functionalization of enantiomerically pure Binol are the most valuable both in terms of chemical yield, enantiomeric excess, reaction time and reaction scaling.

\section{Applications in asymmetric synthesis}

3.1. Catalytic enantioselective Michael-type addition reactions. The Lewis acid-promoted Michael-type addition of 2(trimethylsilyloxy) furan 24 to 3-[(E)-2-butenoyl]-1,3-oxazolidin2-one 25 was examined using a complex mixture generated by $\mathrm{Sc}(\mathrm{OTf})_{3}$ and $\left(R_{\mathrm{a}}\right)$-Binolam 23, both in $5 \mathrm{~mol} \%$ loadings (no evidences have been provided as to the nature of the mixture), as catalyst (Scheme 4). ${ }^{[30,31]}$ The reaction afforded 26 (44-64\% yield) with high diastereoselection ( $>50: 1 d r$ ), though however with only moderate enantioselection (up to $73 \%$ ee). The absolute configuration of the major product was determined by both X-ray diffraction analysis, and chemical derivatization to a known structure. In many examples, the introduction of hexafluoroisopropanol (HFIP) as additive, which is more acidic and has poor coordinating ability, accelerated the reaction increasing the chemical yields. The enantioselectivity of this process was eventually improved (up to $92 \% e e$, Scheme 4) by using the complex mixture resulting from $\mathrm{Cu}(\mathrm{OTf})$ and $t$-BuBox 27. ${ }^{[30,31]}$<smiles>CCN(CC)Cc1cc2ccccc2c(-c2c(O)c(CN(CC)CC)cc3ccccc23)c1O</smiles>

$\left(R_{\mathrm{a}}\right)-23$<smiles></smiles>

$\left(R_{\mathrm{a}}\right)-\mathbf{2 3}(5 \mathrm{~mol} \%)$

$$
\underset{\mathrm{DCM}, 0^{\circ} \mathrm{C}, 4 \AA \mathrm{MS}}{\stackrel{\mathrm{Sc}(\mathrm{OTf})_{3}(5 \mathrm{~mol} \%)}{\longrightarrow}}
$$<smiles>[R]C1=C[C@@H]([C@@H](C)CC(=O)N2CCOC2=O)OC1=O</smiles>

26

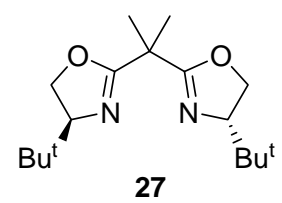

Scheme 4. Enantioselective Michael-type addition promoted by Binolam $\left(R_{\mathrm{a}}\right)-23 / \mathrm{Sc}(\mathrm{OTf})_{3}$.

3.2. Catalytic enantioselective cyanide additions. The preparation of non-racemic cyanohydrins is an important goal for current asymmetric organic synthesis, ${ }^{[32]}$ because the resulting enantiopure cyanohydrins and their derivatives are valuable chiral building blocks for organic synthesis.

As illustrated in Scheme 5, a number of chiral aluminum complexes derived from Binolams 28-32, have been tested as catalysts in the cyanosilylation of aldehydes with trimethylsilylcyanide TMSCN (Scheme 6). It is worth mentioning that although the complexes shown are written as monomeric species, the exact nature of these compounds either in solid or in solution phase, are unknown in most cases. Moreover, it is also worth commenting that, in general, aluminum complexes gave better enantioselections than the analogous titanium or zinc complexes, as it will be shown below.

Specifically, chiral complex $\left(R_{\mathrm{a}}\right)$ - or $\left(S_{\mathrm{a}}\right)-\mathbf{2 8}$, formed by mixing equimolar amounts of $\mathrm{Me}_{2} \mathrm{AlCl}$ and $\left(S_{\mathrm{a}}\right)$-Binolam 23, were successfully employed as catalysts for the overall cyanosilylation of aliphatic, aromatic, heteroaromatic, and $\alpha, \beta$-unsaturated aldehydes. After hydrolysis, cyanohydrins $(R)-33$ were obtained in good yield (45-99\%) and enantioselectivity $(85->99 \% \quad e e)$. 
Advantages over Shibasaki's catalyst ${ }^{[33]}$ were: the operational temperature $\left(-20\right.$ or $\left.-40{ }^{\circ} \mathrm{C}\right)$ was sensibly higher, ${ }^{[34,35]}$ and at the end of the reaction, a simple extractive work-up was sufficient for the recovery of the valuable Binolam ligand, which could be reused without loss in efficiency. Using this protocol it was possible to obtain (S)-33p in excellent yield (>98\%) and high enantioselection $(92 \%$ ee), which is a key intermediate in the synthesis of epothilone $\mathrm{A}^{[33]}$ As a general rule, the $\left(S_{\mathrm{a}}\right)$-chiral complex gave rise to the $(R)$-configured cyanohydrins 33 and, contrarywise, the $\left(R_{\mathrm{a}}\right)$-chiral complex yielded the $(S)$-configured cyanohydrins 33 (Scheme 5).<smiles>CCNCc1cc2ccccc2c(-c2c(OCC)c(CNCC)cc3ccccc23)c1O[Al]</smiles>

$\left(S_{\mathrm{a}}\right)-28$

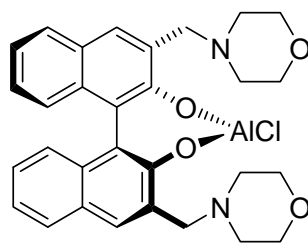

$\left(S_{a}\right)-30$

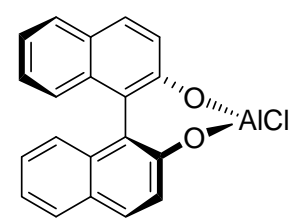

$\left(S_{a}\right)-29$

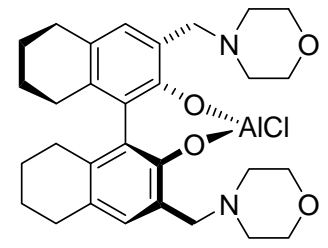

$\left(S_{a}\right)-31$<smiles>Cl[Ge](Cl)(Cl)Oc1ccc2ccccc2c1-c1cc2ccccc2cc1CN1CCOCC1</smiles>

$\left(S_{a}\right)-32$

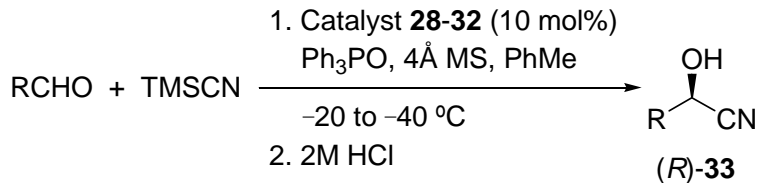

Scheme 5. Binolam-AlCl complexes tested for the cyanosilylation of aldehydes.

In trying to define the bifunctional nature of the catalyst $\mathbf{2 8}$, the activity of monofunctional $\left(S_{a}\right)$-Binol-AlCl complex 29 was studied for the sake of comparison. The efficiency of the former catalyst was found to be much higher than the analogous exhibited by the Binol-derived catalyst, thereby suggesting, but nor proving, the bifunctional nature of the former. In a key experiment that accounts for the specific role played by the amino group in $\mathbf{2 8}$ (either as a Lewis or a Brönsted base) it was found that operating in the presence of triethylamine led to mostly racemized material. These observations, together with the absence of NLE, and the pentacoordinated nature of the aluminum atom, as suggested by the ${ }^{27} \mathrm{Al}$ NMR spectra, reinforce the bifunctional character of complex 28 for this particular reaction, the aluminum atom working as a Lewis acid center whilst the amino group playing the role of a Brönsted or Lewis base. ${ }^{[35]}$ The role of the required additives, namely triphenylphosphine oxide and molecular sieves $4 \AA$ were explored. The action of triphenylphosphine oxide appears to be that of converting catalyst aggregates into the active monomeric species, as suggested by the fact that non-linear effects were observed when working in its absence, while non-linear effects were absent when working in its presence. On the other hand, we have learned that the role of $4 \AA$ molecular sieves is that of incorporating a small amount of water (a 7\% weight loss was determined by thermogravimetry at $400{ }^{\circ} \mathrm{C}$ ), which is capable of generating $\mathrm{HCN}$ by hydrolysis of TMSCN. Accordingly, the working mechanism for this reaction calls for $\mathrm{HCN}$ being captured by the diethylaminomethyl arm, while the $\mathrm{Al}-\mathrm{Cl}$ unit would serve the role of a Lewis acid to fix the incoming aldehyde by means of a strong $\mathrm{Al}-\mathrm{O}=\mathrm{C}$ interaction and a weak one of the type $\mathrm{Cl}-\mathrm{-H}-\mathrm{C}=\mathrm{O}$, as suggested by Corey. ${ }^{[36]}$ The aldehyde in this ternary complex $\mathbf{A}$ is ideally suited to undergo attack by the nearby cyanide unit. The optical yield of the reaction dropped dramatically when an ethyl or a cyano group was directly bonded to the aluminum atom. ${ }^{[35]}$ Final reaction with incoming TMSCN leads to $O$-silylation and liberates $\mathrm{HCN}$ for a subsequent cycle. Accordingly, the appropriate definition for the overall cyanosilylation observed is that of an enantioselective hydrocyanation followed by $O$-silylation.

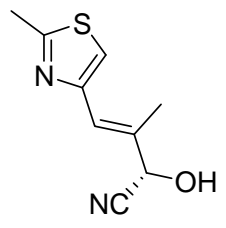

(S)-33p

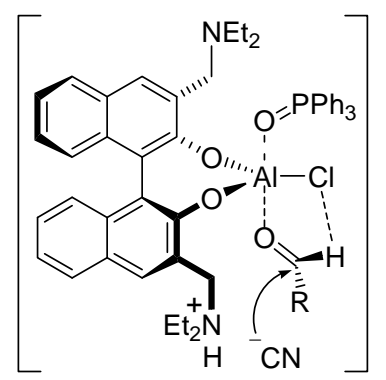

A
Aluminum complexes 30-32 (Scheme 5) have been also examined as catalysts for the enantioselective cyanosilylation of aldehydes, under very similar conditions, the highest conversions and enantioselectivities being achieved by chiral catalytic complex $\left(S_{\mathrm{a}}\right)$-30. Interestingly $\left(S_{\mathrm{a}}\right)$-30 gave excellent enantioselections (99 to $94 \% e e$ ) with aliphatic aldehydes (twelve examples), improving the results of $\left(S_{\mathrm{a}}\right)-\mathbf{2 8}{ }^{\left[{ }^{[28]}\right.}$ The catalytic capacity of $\mathbf{3 0}$ can thus be considered complementary to that of $\mathbf{2 8}$, as this is somewhat more efficient for aromatic and heteroaromatic aldehydes.

Complexes 30-32 have also been explored as catalysts for the enantioselective cyanosilylation of acetophenone otherwise similar reaction conditions than the described in Scheme 5 but introducing some additives such as HMPA or $\mathrm{N}$-methylmorpholine oxide. Unfortunately, low yields of the racemic $O$-silylated cyanohydrins were obtained at the end of the reaction. ${ }^{[28]}$

Binolam-derived titanium(IV) complexes have also been explored as catalysts for enantioselective cyanosylilation. As for the case of aluminum complexes, the titanium(IV) complexes are written as monomeric species, but the exact nature of these compounds either in solid or in solution phase are, in most cases, unknown. In particular, $C_{1}$ symmetric titanium(IV) complex 34 showed catalytic activity. ${ }^{[37]}$ Unfortunately, the cyanosilylation of benzaldehyde at $-40{ }^{\circ} \mathrm{C}$, in the presence, or absence of triphenylphosphine oxide took place with low chemical yield (21 
or $44 \%$, respectively) and moderate identical enantioselection in both cases $(51 \%$ ee $) .{ }^{[37]}$ As previously described, the authors were able to prove the presence of $\mathrm{HCN}$ by ${ }^{1} \mathrm{H}$ NMR experiments. ${ }^{[35]}$ Accordingly, the authors also gave support to a dual activation mechanism, the imidazole moiety acting as Brönsted base to catch $\mathrm{HCN}$ and a titanium atom acting as Lewis acid. A naked-eye analysis of this hypothetical ternary complex clearly suggests serious problems in promoting enantioselective cyanations. Fortunately, closely related complex 35 afforded excellent enantioselections in the cyanosilylation of all type of aldehydes (98-91\% ee for aromatic aldehydes, 98-91\% ee for aliphatic aldehydes, and $90 \%$ ee for $\alpha, \beta$-unsaturated aldehydes). ${ }^{[37]}$

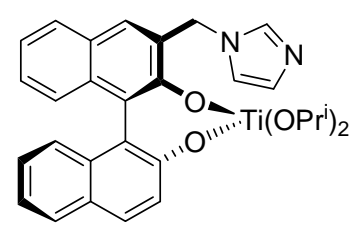

34

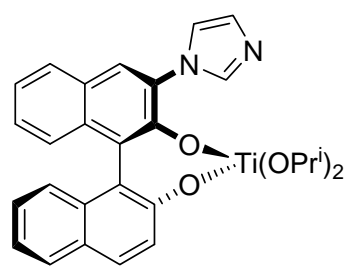

35
Binolam-AlCl complexes $\left(R_{\mathrm{a}}\right)$ - or $\left(S_{\mathrm{a}}\right)$-28 were also effective in promoting the enantioselective synthesis of cyanocarbonates $\mathbf{3 8}$ from aldehydes and methyl cyanoformate (ethyl cyanoformate reacted somewhat poorly), under very mild conditions (addition of reagents in one portion, at room temperature). Best results were obtained in toluene in the presence of $4 \AA$ MS. Chemical yields were excellent and the enantioselections good (up to $81 \%$ ee), but lower than those obtained for the cyanosilylation reaction. Aromatic, heteroaromatic, aliphatic, and $\alpha, \beta$-unsaturated aldehydes exhibited similar chemical behavior and, in all cases analogous enantioselectivities were obtained (Scheme 6) ${ }^{[38,39]}$ All tests are in accordance with the bifunctional mechanism described previously for the cyanosilylation reaction. In other words, the overall cyanocarbonylation process is in fact the result of an initial enantioselective hydrocyanation followed by $O$ methoxycabonylation, a process which liberates the required $\mathrm{HCN}$ for a subsequent cycle.

Binolam-derived titanium(IV) complexes have also been employed for enantioselective cyanocarbonylations of aldehydes. The structure of the actual catalyst is uncertain due to the fact that it results from mixing, at $-15{ }^{\circ} \mathrm{C}$, equimolar amounts of Binolam, $\mathrm{Ti}(\mathrm{OiPr})_{4}$ and the amido alcohol 37. ${ }^{[40]}$ Cyanocarbonylations of aldehydes under these conditions were quite efficient (up to $92 \%$ ee) for all kinds of aldehydes (Scheme 6). The proposed mechanism, which speculates with the possible implication of a monomeric self-assembled catalyst of 1:1:1 stoichiometry, calls for a dual role of the catalyst to activate both the aldehyde and the cyanoetoxycarboxylation reagent employed. In spite of this proposal we temptatively suggest that the reaction conditions employed would likely produce a certain amount of $\mathrm{HCN}$. Accordingly, the overall cyanoetoxycarboxylation could well be the result of an enantioselective hydrocyanation followed by $O$ functionalization. This alternative mechanism should therefore not be discarded. ${ }^{[40]}$

These cyanohydrin derivatives are useful building blocks for the preparation of other enantiomerically pure compounds. ${ }^{[33 \mathrm{~h}]}$ Actually, under acidic hydrolysis, these cyanohydrin derivatives can be converted into the corresponding enantiopure hydroxyacids by chemoselective hydrolysis of $(S)-38\left(\mathrm{R}^{2}=\mathrm{Me}\right)$. OMethoxycarbonyl ethyl esters were obtained in very good yields by alcoholysis of (S)-38 with $2 \mathrm{M} \mathrm{HCl} / \mathrm{EtOH}$, whereas $O$ methoxycarbonyl carboxylic acids were generated by treatment with $12 \mathrm{M} \mathrm{HCl}$ at room temperature. Complete hydrolysis using refluxing $12 \mathrm{M} \mathrm{HCl}$ leads to $\alpha$-hydroxyacids in good yields, but, again, partial hydrolysis (O-protected amides result upon treatment with aqueous $\mathrm{TMSCl}$ ) can be achieved by using the appropriate reagents. ${ }^{[39]}$ Enantiomerically pure $\beta$-amino alcohols can be accessed by reduction with $\mathrm{LiAlH}_{4} \cdot{ }^{[39]}$

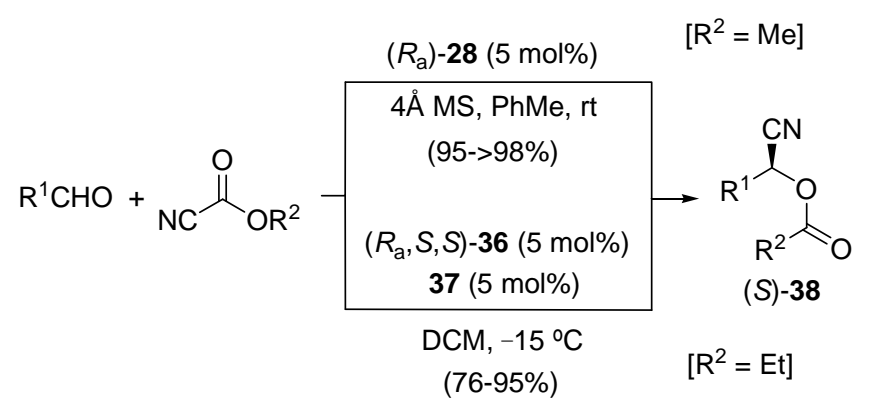<smiles>C[C@@H](Oc1c(CN(C)[C@H](C)c2ccccc2)cc2ccccc2c1-c1c(OC(=O)O)c(CN(C)[C@H](C)c2ccccc2)cc2ccccc12)c1ccccc1</smiles><smiles>CC(=O)NC([Pb])[C@H](O)c1ccccc1</smiles>

$\left(R_{\mathrm{a}}, \mathrm{S}, \mathrm{S}\right)-\mathbf{3 6}$

Scheme 6. Binolam complexes tested in cyanoformylation of aldehydes.

Much effort has been put into the development of simple methods for the enantioselective cyanoacylations using acyl cyanides. The chiral aggregate $\left(S_{\mathrm{a}}\right)$-39 resulting from mixing equimolar amounts of Binolam 23 and $\mathrm{Ti}(\mathrm{OiPr})_{4}$ was found to be a suitable catalyst for the enantioselective synthesis of $O$-benzoyl cyanohydrins $\mathbf{4 0}$ using commercial benzoylcyanide as reagent, for which purpose the use of aluminum complex $\left(S_{\mathrm{a}}\right)$-28 gave much poorer results. Unfortunately, the enantioselection was only modest with all type of aldehydes (56-68\% ee) (Scheme 7) in spite of numerous attempts at improving it. Due to the fact that $\mathrm{HCN}$ can be detected in the reaction mixture, the suggested mechanism calls for an enantioselective hydrocyanation followed by a fast $\mathrm{O}-$ benzoylation by benzoyl cyanide. ${ }^{[41]}$ For this transformation higher catalyst loadings (10 mol\%) were required, in accordance with the lower reactivity of acyl cyanides. 
<smiles>CCN(CC)Cc1cc2ccccc2c(-c2c(O)c(CN(CC)CC)cc3ccccc23)c1O</smiles>

$\left(S_{a}\right)-39$

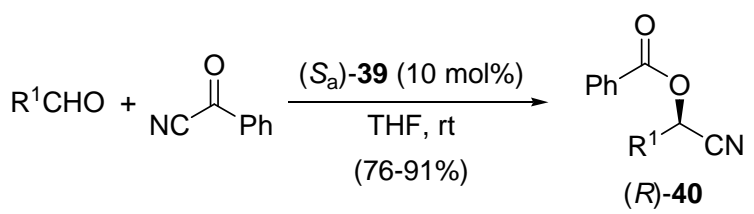

Scheme 7. Binolam-Ti(IV) aggregate $\left(S_{\mathrm{a}}\right)-39$ tested in the cyanobenzoylation of aldehydes.

The only reported access to enantiopure cyanohydrin $O$ phosphates $(R)-\mathbf{4 1}$ involves the use of Binolam-AlCl $\left(S_{\mathrm{a}}\right)-\mathbf{2 8}$ as chiral catalyst. This is quite remarkable because cyanohydrin $O$ phosphates $(R)-\mathbf{4 1}$ are very difficult to obtain in optically pure form by direct phosphorylation of enantioenriched cyanohydrins in the presence of a base, partial racemization being the main drawback. ${ }^{[42,43]}$ A large series of aldehydes reacted in toluene at room temperature with commercial diethyl cyanophosphonate in the presence of the chiral complex $\left(S_{\mathrm{a}}\right)-\mathbf{2 8}(10 \mathrm{~mol} \%)$, no additives being required to facilitate the reaction, such as occurred in previous examples dealing with cyanosilylations or cyanoformylations promoted by the same catalyst (Scheme 8). ${ }^{[42,43]}$ Chemical yields and enantioselectivities were very high and the chiral ligand could be recovered almost quantitatively at the end of the reaction after an extractive acidic/basic work up. A thorough study of the mechanism of this reaction was carried out. The existence of a strongly positive NLE suggested that a monomeric catalytic species, in equilibrium with inactive, or slower acting, dimeric or oligomeric species (the so called "reservoir effect") could be the catalytically active complex. In addition, computations at the HF/6-31G* level served to delimit the relative importance of the direct cyanophosphorylation route versus the indirect route involving hydrocyanation followed by $O$ phosphorylation. The data clearly supported the most likely involvement of the indirect route for which both $\mathrm{HCN}$ and $\mathrm{HNC}$ modes of addition were found to be active routes to be considered. Eventually, it was found that the lowest energy barrier corresponded to the addition of HCN to the Si face of the aldehyde, as shown in transition state $\mathbf{B}$ (Scheme 8). ${ }^{[39]}$ More important, the results of these computations are in accordance with the experimental observations.

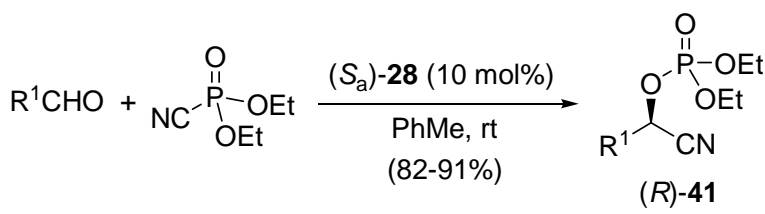

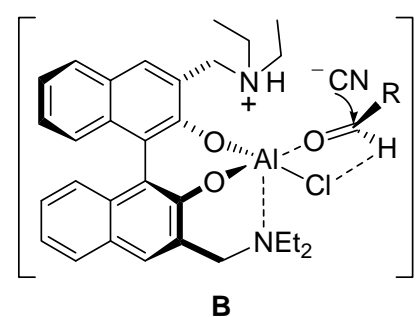

Scheme 8. Binolam $\left(S_{\mathrm{a}}\right)$-28 tested in the cyanophosphorylation of aldehydes.

Cyanophosphates $\mathbf{4 1}$ were found to be stereochemically stable upon standing at room temperature for months. Their utility in organic synthesis was surveyed and contrasted with the cyanocarbonate analogs. Although in both cases racemization occurred under basic or acidic media, the treatment of $(R)-\mathbf{4 1}\left(\mathrm{R}^{1}=\right.$ $\mathrm{Ph}$ ) with anhydrous $\mathrm{HCl} / \mathrm{EtOH}$, at $0{ }^{\circ} \mathrm{C}$, yielded highly enantioenriched $(R)$-O-phosphorylmandelate (with less than $3 \%$ loss of enantiomeric purity). Cyanohydrin derivatives, obtained from $\alpha, \beta$-unsaturated aldehydes, underwent $\mathrm{S}_{\mathrm{N}} 2$ ' substitution reactions, with carbo- or heteronucleophiles catalyzed by iridiumor palladium. ${ }^{[44]}$ In situ generated dialkyl cuprates also give rise to $\mathrm{S}_{\mathrm{N}} 2$ ' substitution processes. ${ }^{[45]}$ The final $\alpha, \beta$-unsaturated nitriles 42 , 43 and 44 thus obtained were found to be very attractive intermediates in organic synthesis. Thus, $\mathbf{4 2}$ is as a direct precursor of $\gamma$-amino acids, ${ }^{[44]}$ compound $43\left(\mathrm{R}^{1}=\mathrm{C}_{5} \mathrm{H}_{11}\right)$ is an intermediate in the synthesis of coriolic acid, ${ }^{[4]}$ and the enantiomerically enriched products $44\left(\mathrm{R}^{1}=\mathrm{C}_{5} \mathrm{H}_{11}, \mathrm{R}^{2}=\mathrm{Me}\right)$ were the precursors of the preparation of the yellow mealworm Tenebrio molitor L (R)-45 and its corresponding enantiomer (S)-45 ${ }^{[45]}$ (Scheme 9). An important drawback of these allylic substitutions is to control the final configuration of the alkenes due to the small stereoelectronic hindrance of the cyano-substituent. ${ }^{[44,45]}$

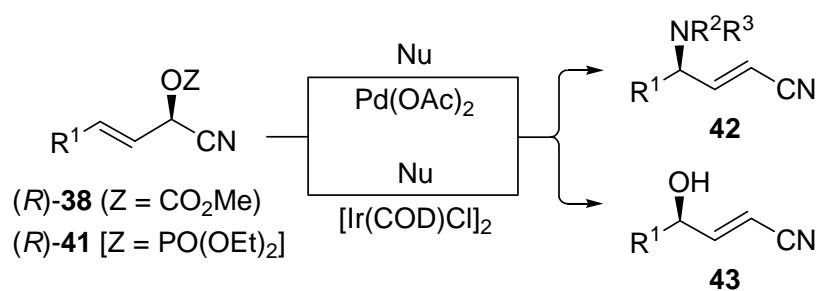

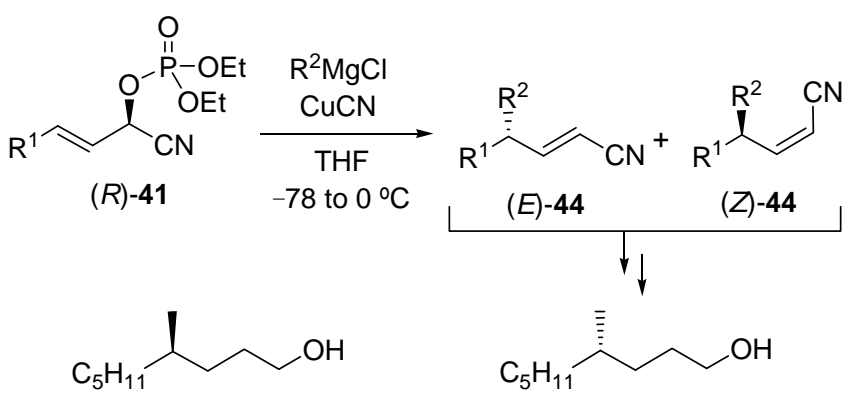

(R)-45 sex pheromone

(S) -45 
Scheme 9. Synthetic utility of the unsaturated cyanohydrin derivatives $\mathbf{3 8}$ and 41.

All attempts at extending the use of Binolam-AlCl $\mathbf{2 8}$ as an enantioselective catalyst for the Strecker addition of cyanide derivatives to imines, led to racemic compounds. ${ }^{[4]}$ Recently, an Strecker-type reaction was reported using ligand $\mathbf{4 6}$ as organocatalyst (Scheme 10). ${ }^{[48]}$ This product was prepared from the chiral dialdehyde $\left(S_{\mathrm{a}}\right)$-19 and prolinamide, followed by oxidation with MCPBA at very low temperature. The addition of TMSCN to ketoimines catalyzed with $\mathbf{4 6}$ afforded $N$-tosylamino nitriles $(R)-\mathbf{4 7}$ in very good yields and excellent enantioselections (90-99\% ee). It is worth mentioning that a large amount of 1-adamantanol was required as additive in order to reach high levels of enantioselection (Scheme 10). Presumably, this addition induces the formation of $\mathrm{HCN},{ }^{[48]}$ as proved for previous cases.<smiles>O=C1NC(c2cc3ccccc3c(-c3c([C@H]4NC(=O)[N+]5([O-])CCCC45)cc4ccccc4c3O)c2O)[N+]2(O)CCC[C@H]12</smiles>

$\left(S_{a}\right)-46$
Scheme 10. Strecker-type reaction onto ketimines mediated by the organocatalyst 46 .

In summary, metal-based catalysts, derived from bifunctional Binolam ligands, appear to be ideally suited for the one-pot synthesis of enantiomerically enriched cyanohydrin derivatives. Worthy of note is the fact that the Binolam ligand can be recovered and reused without a significant loss of activity. Traces of HCN are either present in the commercial cyanide source employed, or in situ formed by hydrolysis or alcoholysis. This, together with other relevant proves, supports the proposal that bifunctional Binolammetal catalysts work as Lewis acid-Brönsted base (LABB) catalysts followed by an $O$-functionalization (silylation, phosphorylation, alkoxycarbonylation or acylation) step, which liberates $\mathrm{HCN}$ for a subsequent cycle.

3.3. Enantioselective hydrophosphonylation of aldehydes. The hydrophosphonylation of aldehydes (Pudovic reaction), involves the addition of diethyl phosphite which is in tautomeric equilibrium with hydrogen diethylphosphonate $\left[\mathrm{H}(\mathrm{OEt})_{2} \mathrm{P}=\mathrm{O}\right]$. Chiral Binolamderived aluminum complex $\left(R_{\mathrm{a}}, S, S\right)-\mathbf{4 8}(10 \mathrm{~mol} \%)$ has been proven to be an appropriate catalyst for the eantioselective hydrophosphonylation of aldehydes, enriched $\alpha$ hydroxyphosphonates (S)-49 being obtained in high yields and good enantioselectivities (up to $84 \%$ ee). The reaction, which is of wide scope as either aromatic, heteroaromatic, and aliphatic aldehydes (Scheme 11) ${ }^{[49]}$ gave smilar results, has been proposed to involve a bifunctional LABB mechanism to that illustrated above for the addition of HCN.

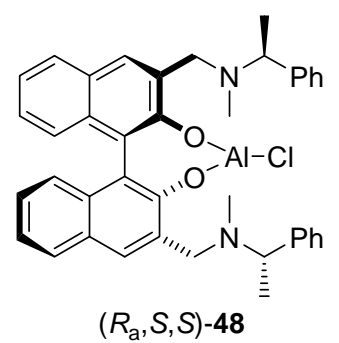

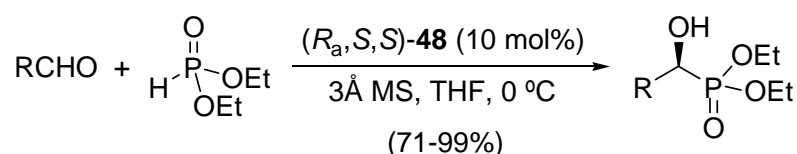

(S)-49

Scheme 11. Enantioselective addition of alkynylzinc compounds onto aldehydes.

\subsection{Enantioselective aza-Morita-Baylis-Hillman reaction. The} aza-Morita-Baylis-Hillman (aza-MBH) reaction can be defined as a condensation of an electron-poor alkene and an aldimine catalyzed by a tertiary amine or phosphine. ${ }^{[50]}$ Usually, this reaction is very slow and the enantioselective approach has proven to be a difficult task to achieve. Sophistication reaches the point where Binolam I derivatives were unable to catalyze the reaction, whereas Binolam II derivatives were applicable. Thus, single aminomethyl armed structures 50-52 gave satisfactory yields and very high enantioselections of the final product $53 .^{[51,52,53]}$ Under the optimized reaction conditions at $-15{ }^{\circ} \mathrm{C}$, with a $10 \mathrm{~mol} \%$ of catalyst loading, in a mixture of toluene and CPME (cyclopentyl methyl ether) as solvent, the best enantioselection ( $88-95 \%$ ee) was achieved using chiral organocatalyst $\left(S_{\mathrm{a}}\right)$-52d (Scheme 12 and Table 1). Compounds $\left(S_{\mathrm{a}}\right)-\mathbf{5 1 b},\left(S_{\mathrm{a}}\right)-\mathbf{5 2 c},\left(S_{\mathrm{a}}\right)-\mathbf{5 2 e}$ and $\left(S_{\mathrm{a}}\right)-\mathbf{5 2 f}$ also promoted this reaction with very good conversions and high enantioselections, but the scope was quite limited.

Table 1. Enantioselective aza-MBH catalyzed by 50-52.

\begin{tabular}{llll}
\hline Entry & $\left(S_{\mathrm{a}}\right)$-Ligand & $\mathbf{5 3}{\text { Yield }(\%)^{[\mathrm{a}]}}$ & $\mathbf{5 3 ~ e e}$ \\
\hline 1 & $\mathbf{5 0}$ & $\mathrm{nd}^{[\mathrm{b}]}$ & $\mathrm{nd}^{[\mathrm{b}]}$ \\
2 & $\mathbf{5 1 a}$ & 5 & 24 \\
3 & $\mathbf{5 1 b}$ & 85 & 79 \\
4 & $\mathbf{5 2 a}$ & 62 & 87 \\
5 & $\mathbf{5 2 b}$ & 97 & 90 \\
6 & $\mathbf{5 2 c}$ & 90 & 91 \\
7 & $\mathbf{5 2 d}$ & 88 -quant. & $88-95$ \\
8 & $\mathbf{5 2 e}$ & 72 & 83 \\
9 & $\mathbf{5 2 f}$ & 99 & 93 \\
\hline$[\mathrm{a}]$ & Reaction run with methyl vinyl ketone and $N$-tosylimine
\end{tabular}
with $\mathrm{R}^{2}=p-\mathrm{ClC}_{6} \mathrm{H}_{4} \cdot[\mathrm{b}] \mathrm{nd}=$ not detected. 
<smiles>CN(Cc1cc2ccccc2c(-c2c(O)ccc3ccccc23)c1O)c1ccccc1</smiles>

$\left(S_{\mathrm{a}}\right)-50$

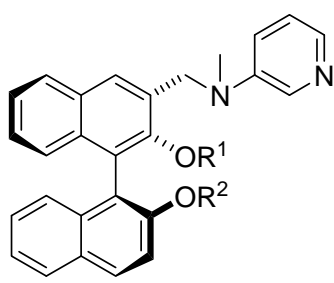

$\left(S_{a}\right)-51 a, R^{1}=H, R^{2}=M e$

$\left(S_{a}\right)-51 b, R^{1}=M e, R^{2}=H$
$\left(S_{a}\right)-52 a, R=H$

$\left(S_{a}\right)-52 b, R=M e$

$\left(S_{\mathrm{a}}\right)-52 \mathrm{c}, \mathrm{R}=\mathrm{Et}$

$\left(S_{\mathrm{a}}\right)-52 \mathrm{~d}, \mathrm{R}=\operatorname{Pr}^{\mathrm{i}}$

$\left(S_{\mathrm{a}}\right)-52 \mathrm{e}, \mathrm{R}=\mathrm{Bu}^{\mathrm{t}}$

$\left(S_{\mathrm{a}}\right)-\mathbf{5 2 f}, \mathrm{R}=\mathrm{Bn}$

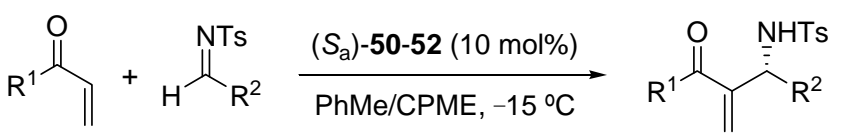

53
Scheme 12. Aza-MBH reactions promoted by organocatalysts $\left(S_{\mathrm{a}}\right)-\mathbf{5 0 - 5 2}$.

Catalyst action appears to involve the dual activation of both nucleophile and electrophile, as suggested by several indirect evidences. If both Brönsted acid and Lewis base units were conveniently positioned, the acid unit could activate a carbonyl group of the $\alpha, \beta$-unsaturated system and, consequently, the Lewis base unit would react with the $\beta$-position of the substrate in transition state $\mathbf{C}$. The subsequent Mannich-type addition, followed by the retro-Michael-type step would give finally the desired product 53. This bifunctional mechanism was also supported by several experiments, as it is the fact that the reaction performed with organocatalyst $\left(S_{\mathrm{a}}\right)-\mathbf{5 0}$ was unsuccessful due to the lack of the heteroaromatic nitrogen, again reinforcing its crucial role in a dual mechanism. ${ }^{[50-53]}$

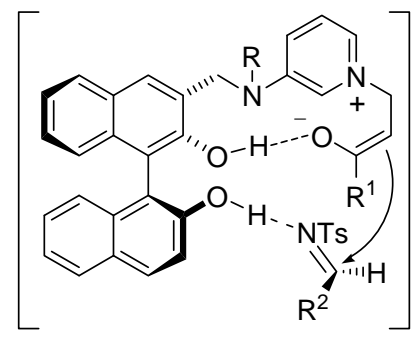

C

3.5. Enantioselective nitroaldol reaction. The nitroaldol (Henry) reaction ${ }^{[54]}$ has been the goal of many enantioselective strategies due to the high functional density present on these structures at the end of the reaction. Binolam I compounds, due to the topological disposition of their ligating arms (according to the X-ray diffraction data of Binolam ( $\mathrm{R}=\mathrm{Et})$, the $\mathrm{C} 2 \mathrm{C} 1 \mathrm{C} 1{ }^{\prime} \mathrm{C} 2$ ' dihedral angle is $90.3^{\circ}$ ) are ideally suited for forming octahedral complexes. Accordingly, Binolams have been reported to form $3: 1$ lanthanide(III) triflate complexes $\mathbf{5 4}$ (Scheme 13a) quantitatively, ${ }^{[55]}$ by simply mixing 3 equiv. of ligand 23 with 1 equiv. of lanthanide(III) triflate in dry acetonitrile. The resulting hexacoordinated complexes $\mathbf{5 4}$ were found to be shelf stable solids, though nevertheless kinetically labile, characterized by having an extra chiral center at the lanthanide atom and an extended array of acid and basic sites. ${ }^{[56]}$ Among the lanthanide complexes studied 54Ln, the lanthanum complex 54La was the most adequate for the enantioselective addition of nitromethane to aromatic, aliphatic and $\alpha, \beta$-unsaturated aldehydes. The reaction occurred at $-40{ }^{\circ} \mathrm{C}$ in dry acetonitrile using 54La $(5 \mathrm{~mol} \%)$ and an equimolar amount $(5$ mol\%) of an amine such as DBU, or proton sponge ${ }^{\circledR}[1,8$ bis(dimethylamino)naphthalene], slightly better with the later base (Scheme 13a). The absence of non-linear effects is in agreement with the involvement of kinetically labile, monomeric 3:1 complexes. The hypothetical mechanism proposed calls for a prior deprotonation step upon precatalyst $\mathbf{5 4}$, thereby giving rise to the actual catalyst presumably incorporating a Lewis acid-Lewis baseBrönsted base arrayed network, where the lanthanum Lewis acid should ligate nitromethane and get deprotonated by the amine Brönsted base site. Final coordination of the aldehyde should then be followed by carbon-carbon bond formation, and the eventual recovery of the catalytic active complex. ${ }^{[55]}$

More interestingly, complex 54La (25 mol\%) was also effective in catalyzing the nitroaldol reaction of $\alpha$-trifluoromethyl ketones with nitromethane (Scheme 13b) in an enantioselective manner, a prior unachieved goal. ${ }^{[57]}$ Alkyl, alkynyl, benzyl, and aryl trifluoromethyl ketones were allowed to react in acetonitrile at -40 ${ }^{\circ} \mathrm{C}$ for $4 \mathrm{~d}$ in the presence of a proton sponge ${ }^{\circledR}(25 \mathrm{~mol} \%)$ furnishing tertiary nitroaldols (S)-56 in good yields and high enantioselectivities (67-98\% ee) (Scheme 13b). Reduction of the nitro group with "nickel boride" yielded the corresponding aminoalcohols having a chiral quaternary carbon with no loss of enantiomeric purity. The absolute configuration of this aminoalcohol, and therefore of the nitroaldol $\mathbf{5 6}$ precursor, was assigned from the sign of the Flack parameter upon the X-ray diffraction structure. The hypothetic mechanism for this nitroaldol condensation calls for an specific chelating ability of the $-\mathrm{COCF}_{3}$ unit opposite to that of an aldehyde $-\mathrm{COH}$, in accordance with the opposite configurations of the final adducts $(R)-55$ and $(S)-56 .^{[57]}$ 


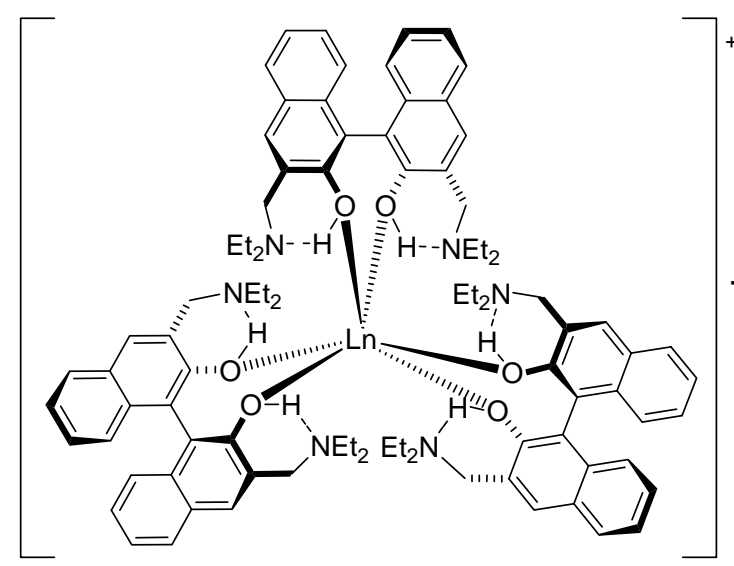

$\left(\Delta, S_{a}, S_{a}, S_{a}\right)-54 L n$

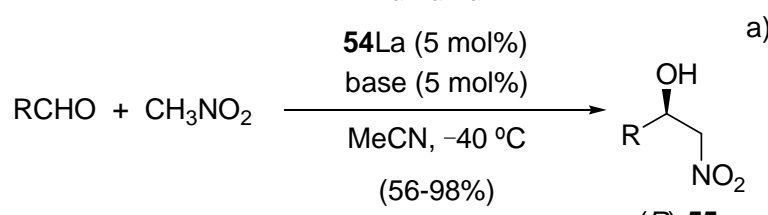

$(R)-55$

b)

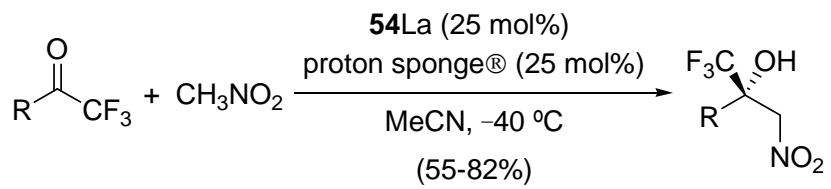

(S)-56

Scheme 13. Enantioselective nitroaldol (Henry) reaction promoted by complex 54La.

3.6. Enantioselective organozinc compound additions. The addition of organozinc compounds onto $\mathrm{C}=\mathrm{O}$ or $\mathrm{C}=\mathrm{N}$ double bonds is a current practice for evaluating the efficiency of a chiral ligand. Binolam ligands I and II have been studied in the diphenyl or diethylzinc, and zinc phenylacetylide onto carbonyl compounds mainly aldehydes. Binolam type $\mathbf{I}$, their precursory amides 22, and partially hydrogenated ligands $\left(S_{\mathrm{a}}\right)-\mathbf{5 7}$ and $\left(S_{\mathrm{a}}\right)$-58 were examined for catalytic capacity. The higher catalytic activity on the enantioselective diphenylzinc addition onto aldehydes corresponded to $\left(S_{\mathrm{a}}\right)-57^{[28,29]}$ Both aromatic and aliphatic aldehydes gave good yields and excellent enantioselectivities of alcohols 59 (90-97\% ee and $92-99 \%$ ee, respectively), even for linear aliphatic aldehydes (Scheme 14a). ${ }^{[28,29]}$ NMR spectroscopic studies revealed the presence of different zinc alkoxides (oligomers or clusters) derived from the reaction between ligand and organozinc reagent, thus suggesting that the catalytically active species could even possess three or four metallic centers. ${ }^{[25][26]}$ The reaction has been successfully extended to functionalized arylzinc reagents, prepared in situ from the corresponding aryliodides (as for example, $m$-iodoanisole, methyl $p$-iodobenzoate and $m$ iodobenzonitrile) and diethylzinc. Both chemical yields and enantioselectivities were very high when the reaction was carried out at $0{ }^{\circ} \mathrm{C}$ either with aliphatic or aromatic aldehydes (Scheme $14 \mathrm{a}){ }^{[58]}$

Diethylzinc, however, was added to aldehydes with poor enantioselectivity. Eventually, the authors found that the presence of 1,2 equiv. of $\mathrm{Ti}\left(\mathrm{OPr}^{\mathrm{i}}\right)_{4}$ was required, together with the Binolam ligand $\left(S_{\mathrm{a}}\right)-58(10 \mathrm{~mol} \%)$ for efficiency in the adition to aromatic aldehydes, thereby furnishing chiral alcohols (S)-60 in good yields and high enantioselectivity (64-98\% ee, Scheme 14b). ${ }^{[59]}$ Other Binol-derived compounds were eventually found to be more efficient than Binolams.<smiles>Oc1c(CN2CCOCC2)cc2c(c1-c1c(O)c(CN3CCOCC3)cc3c1CCCC3)CCCC2</smiles>

$\left(S_{a}\right)-57$<smiles>Oc1ccc2c(c1-c1c(O)cc3c(c1CN1CCOCC1)CCCC3)CCCC2</smiles>

$\left(S_{a}\right)-58$ a)

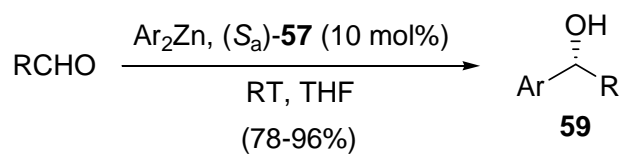

b)

Scheme 14. Enantioselective addition of organozinc compounds onto aldehydes.

Bifunctional ligand $\left(S_{\mathrm{a}}\right)-\mathbf{5 7}$ was employed to catalyze the enantioselective alkynylzinc additions onto aldehydes, thereby leading to chiral propargylic alcohols $\mathbf{6 1}$, which are of great utility in organic synthesis. The reactions were carried out at room temperature by mixing the ligand $\left(S_{\mathrm{a}}\right)-57(20 \mathrm{~mol} \%)$, diethylzinc (4 equiv), $\mathrm{Ti}\left(\mathrm{OPr}^{\mathrm{i}}\right)_{4}$ ( 1 equiv), and phenylacetylene (4 equiv) in THF. Aromatic aldehydes reacted in good yields and in high selectivities (67-98\% ee, Scheme 15a), but linear aliphatic aldehydes gave lower enantioselectivities ( $67 \%$ ee from $n$-octanal). On the other hand, addition to ketones required the use of $40 \mathrm{~mol} \%$ of $\mathrm{Ti}\left(\mathrm{OPr}^{\mathrm{i}}\right)_{4}$ in 1,4-dioxane as solvent to obtain enantiomerically enriched tertiary alcohol 63 which contains a quaternary carbon, in $69 \%$ ee (Scheme 15). ${ }^{[28]}$ A $20 \mathrm{~mol} \%$ of $\left(S_{\mathrm{a}}\right)-57$ allowed the preparation of polyfunctionalized 62 in $69 \%$ enantiomeric purity (Scheme $15 b){ }^{[28]}$ 


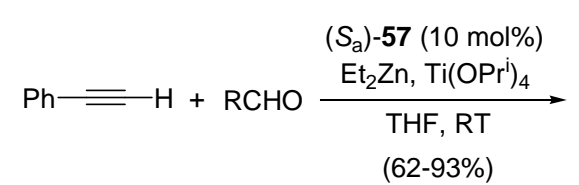

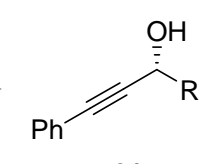

a)

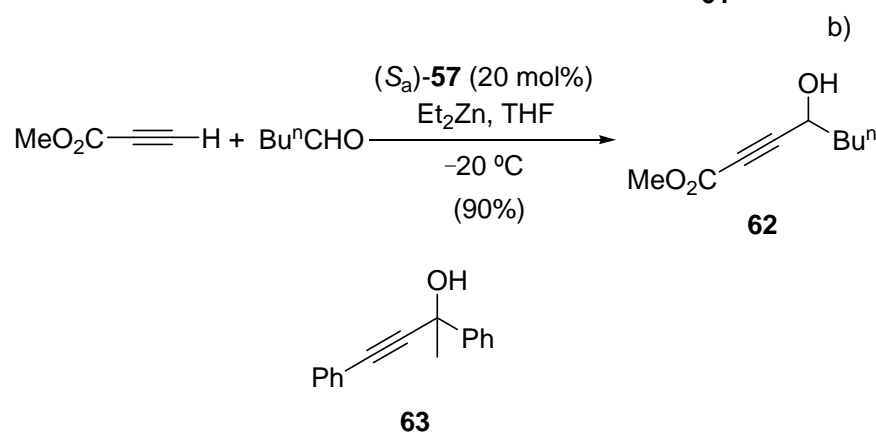

Scheme 15. Enantioselective addition of alkynylzinc compounds onto aldehydes.

3.7. Enantioselective $\alpha$-alkylation of iminoesters. Activated enolates derived from ketimino glycinate 64, or aldimino alaninate 65, have been employed for the asymmetric synthesis of $\alpha$-amino acids, for which purpose enantioselective alkylations with electrophilic reagents and Michael-type addition reactions onto electrophilic alkenes were explored using chiral PTC agents. ${ }^{[60]}$ The versatility of this strategy allows to obtain $\alpha$-substituted- $\alpha$ amino acids starting from ketimine 64, or $\alpha, \alpha$-disubstituted- $\alpha$ amino acids employing aldimine 65 instead. The capacity of Binolam and Binolam derivatives to catalyze these processes has been explored in several ocasions. In particular, Binolam 23 was examined as precatalyst for the direct alkylation of iminoglicinate 64 on the expectation that quaternization of the $\alpha$-carbon would occur in situ thereby generating the actual PTC catalyst. Best results obtained involved the use of $40 \% \mathrm{KOH}$ in a two-phase system. ${ }^{[61]}$ Enantiomerically pure bis-ammonium salt 66, prepared in two steps from the corresponding Binaphthol $\mathbf{I}$, was assayed as chiral PTC agent $\left(1 \mathrm{~mol} \%, \mathrm{Ar}=4-\mathrm{CF}_{3} \mathrm{C}_{6} \mathrm{H}_{4}, \mathrm{NR}_{3}=\mathrm{NEt}_{3}\right)$ in the 1,4-addition reaction of tert-butyl iminoglycinate 64 with methyl acrylate, $N, N$-diphenyl acrylamide, acrylonitrile, phenyl vinyl ketone, and phenyl vinyl sulfone, using chlorobenzene as solvent and 2 equiv of $\mathrm{Cs}_{2} \mathrm{CO}_{3}$ as solid base. Although the yields obtained of the $\alpha$-alkylated products 67 were moderate to high $(50-100 \%)$, enantioselectivities were found to be unsatisfactory $(32-75 \%$ ee, Scheme 16a). ${ }^{[25]}$

The preparation of non-proteinogenic quaternary $\alpha$-methyl- $\alpha$ amino acid (S)-69, an artificial sweetener, could be achieved starting from iminoester 68. The best reaction conditions for obtaining the $\alpha$-benzylalanine (68\% ee) are shown in Scheme $16 \mathrm{~b}$. The most suitable chiral PTC agent was found to be Binolam 23, employed in a $5 \mathrm{~mol} \%$ loading in toluene, the selected base being $\mathrm{NaOH}$ (2 equiv). ${ }^{[61]}$

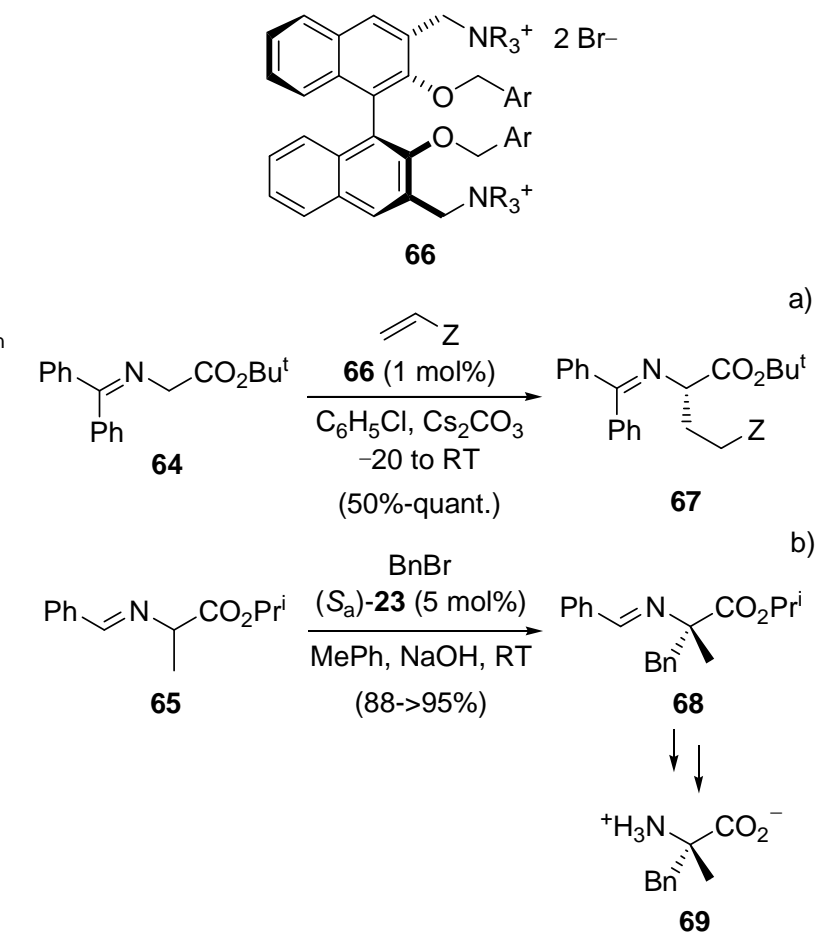

Scheme 16. Enantioselective PTC additions and alkylations promoted by Binolam I derivatives.

3.8. Enantioselective alkane oxidations. The enantioselective C$\mathrm{H}$ oxidation of alkanes is a field of great prospect and usefulness, for which purpose enzyme like catalysts are being explored. Complexation of ligand $\left(S_{a}\right)-\mathbf{7 0}$ with iron(III) salts yielded a dinuclear complex which was tested as catalyst for the enantioselective oxydation of alkanes to yield alcohols. The authors employed $m$-chloroperbenzoic acid (mCPBA) or $\mathrm{N}$ methylmorpholine oxide (NMO) as stoichiometric oxidants. Unfortunately, under these conditions, the enantioseletivity was extremely low for the $(R)$-isomer $(\leq 10 \%)$ of the corresponding alcohol. ${ }^{[62]}$<smiles>CN(Cc1ccccn1)Cc1cc2ccccc2c(-c2c(O)c(CN(C)Cc3ccccn3)cc3ccccc23)c1O</smiles>

$\left(S_{a}\right)-70$

3.9. Enantioselective aldol reactions. The first direct asymmetric aldol reaction of aryl ketones with aryl aldehydes reported to date was catalyzed by the chiral metal complex generated by reacting semicrown chiral ligand 71 (20 mol\%) with diethylzinc (40 mol\%). Although the reaction took approximately 5 days to completion, both the chemical yield (36-97\%) of 72 and the enantioselectivity were good. Actually an $80 \%$ ee was obtained for the reaction of acetophenone and furfural. The proposed mechanism calls for a dinuclear zinc complex where the zincate enol of the ketone attacks the aldehyde (Scheme 17). ${ }^{63}$ 
<smiles>Oc1c(CN2CCCC2C(O)(c2ccccc2)c2ccccc2)cc2ccccc2c1-c1c(O)c(CN2CCCC2C(O)(c2ccccc2)c2ccccc2)cc2ccccc12</smiles>

$\left(R_{a}, S, S\right)-71$

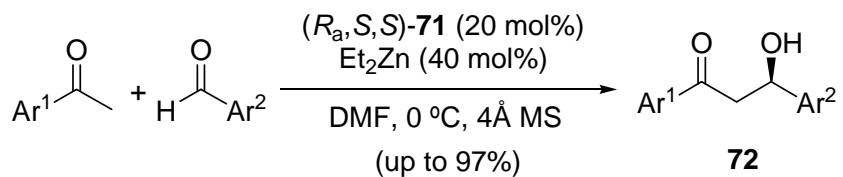

Scheme 17. Enantioselective Michael-type addition promoted by Binolam $\left(R_{\mathrm{a}}, S, S\right)-71 / \mathrm{Sc}(\mathrm{OTf})_{3}$.

3.10. Enantioselective transformations promoted by Binolam precursors 22 and 72. Binolam precursory amides 22 and 72 have also been tested as catalysts for several enantioselective transformations. Herein we briefly describe their most relevant applications as enantioselective catalysts for the addition of dialkyl or diphenylzinc to carbonyl compounds, , ${ }^{[24][64,65,66,67,68]}$ for the Simmons-Smith cyclopropanations, ${ }^{[24][69]}$ for aldol reactions, ${ }^{[70]}$ and for the epoxidation reactions (Scheme 18). ${ }^{[71,72]}$

The enantioselective diethylzinc addition onto aldehydes was performed directly at $0{ }^{\circ} \mathrm{C}$ by using a $10 \mathrm{~mol} \%$ of bisamide $\left(R_{\mathrm{a}}\right)-22$ $\left(\mathrm{R}^{1}=\mathrm{R}^{2}=\mathrm{Bu}^{\mathrm{n}}\right)$ obtaining, after hydrolysis alcohols $(R)-73$ in good yields and very high enantioselectivities $(91-99 \%$ ee) (Scheme 18a). ${ }^{[24,64]}$ Identical enantioselection range was determined in the analogous reaction with diphenylzinc as reagent. In this reaction the selected ligand was rather $\left(S_{\mathrm{a}}\right)-\mathbf{2 2}\left(\mathrm{R}^{1}=\mathrm{R}^{2}=\operatorname{Pr}^{\mathrm{i}}\right)$ than the other $N$-substituted Binolams. ${ }^{[65]}$ In both examples, the ethyl and the phenyl group were efficiently transferred to aromatic heteroaromatic, and aliphatic aldehydes. ${ }^{[24,64,65]}$ In order to recover the chiral ligand from the reaction mixture, polymer-supported amides $\left(R_{\mathrm{a}}\right)-2^{[66,67]}$ and $\left(R_{\mathrm{a}}\right)-\mathbf{7 2} 2^{[67]}$ incorporating a polystyrene brand were explored for catalysis. In both cases it was necessary the presence of catalytic amounts of $\mathrm{Ti}\left(\mathrm{OPr}^{\mathrm{i}}\right)_{4}$ to perform the diethylzinc addition at $0{ }^{\circ} \mathrm{C}$, the ligand $\left(R_{\mathrm{a}}\right)-22$ being the most effective (Scheme 18b and d). Moreover, alcohols $(R)-73$ were also obtained when a dendrimeric skeleton was attached to the nitrogen atom of ligand $\left(R_{\mathrm{a}}\right)-\mathbf{2 2}$ under otherwise identical reaction conditions. Moderate enantioselectivities $(46-72 \%$ ee) (Scheme $18 \mathrm{c})$ were obtained in this case. Obviously, the advantage of using polystyrene or dendrimer-supported $\left(R_{\mathrm{a}}\right)$-22 as catalysts is that they could be satisfactorily separated by filtration and further reused for another batch.

Amide $\left(R_{\mathrm{a}}\right)-\mathbf{2 2}\left(\mathrm{R}^{1}=\mathrm{R}^{2}=\mathrm{Et}\right)$ has also been explored as catalyst for the asymmetric Simmons-Smith reaction upon $E$ allylic alcohol 74 (cinnamyl alcohol) thus leading to cyclopropanes 75 . The absolute configuration of the final products is not given here because it strongly depends of the geometry and the substituents of the alkene. Nevertheless, for sake of clarity, only one case is illustrated: cyclopropane $(1 R, 2 R)-75$ was obtained in $94 \%$ ee when cinnamyl alcohol was used as starting material (Scheme 18e). ${ }^{[24,69]}$

The enantioselective aldol reaction of glycine with benzaldehyde could be mediated by supramolecular assemblies composed by lipidic species, a hydrophobic pyridoxal, and copper(II) ions. Unfortunately, the enantioselection achieved for aldol $\mathbf{7 6}$ was very low when the $\left(S_{\mathrm{a}}\right)$-22 was the central chiral part of the mentioned supramolecular entity $(46 \%$ ee $)$. The absolute configuration of the stereogenic centers was also difficult to generalize. The stereochemical microenvironment around the copper ion involved in the in the intermediate Schiff-base complex, which allowed either Si or Re attack onto benzaldehyde (Scheme 18f), is extremely complex.

Finally, the $C_{2}$-symmetric diamide $\left(R_{\mathrm{a}}\right)$-22 was inserted in two handles around of a porphyrin core imitating the model of the natural proteins. The resulting chiral iron(III) complexes exhibited moderate enantioselections in the epoxidation of alkenes by using iodosylbenzene as oxidant (Scheme $18 \mathrm{~g}$ ). ${ }^{[71,72]}$ Styrene derivatives were found to be the ideal substrates for this epoxidation reaction, which leads to chiral epoxides $\mathbf{7 7}$ in good yields.

\section{Conclusions}

Jacobsen coined the term "privileged" catalysts to those capable of promoting a large variety of different enantioselective transformations. ${ }^{[73]}$ As illustrated above, Binolams and Binolam complexes have been proved to catalyze numerous enantioselective additions involving enolate derivatives, such as the aza-MoritaBaylis-Hillman (aza-MBH) reaction, nitroaldol (Henry) reaction, Michael-type addition, and $\alpha$-alkylation reactions as well as for the addition of organozinc reagents to carbonyls and imine derivatives. In addition, they have been found highly valuable for the enantioselective cyanation of aldehydes. In our view, the bifunctional structure of Binolams and of their metal complexes invites these species to promote a dual catalytic action in activating both the nucleophilic and the electrophilic species. In our view, it is this capacity that elevates Binolams to the category of privileged catalysts (or ligands). Accordingly, the future of Binolams in enantioselective catalysis is still very promising.

\section{Acknowledgments}

This work has been supported by the DGES of the Spanish Ministerio de Ciencia e Innovación (MICINN) and Ministerio de Educación y Ciencia (MEC) (Consolider INGENIO 2010 CSD2007-00006, CTQ200762771/BQU, CTQ2007-62952/BQU, CTQ2004-00808/BQU, CTQ200402375/BQU, BQU2001-0724-C02, PB96-0203, and PB97-0123), Generalitat Valenciana (GVDOC00-14-02, CTIOIB/2002/320, GRUPOS03/134 and GV05/144), and by the University of Alicante. Thanks are also due to CESCA (Centre de Supercomputació de Catalunya), CESGA (Centro de Supercomputación de Galicia) and the UIB (Universitat de les Illes Balears) for their generous allocation of computation time. 
Received: ((will be filled in by the editorial staff))

Published online: ((will be filled in by the editorial staff)) 


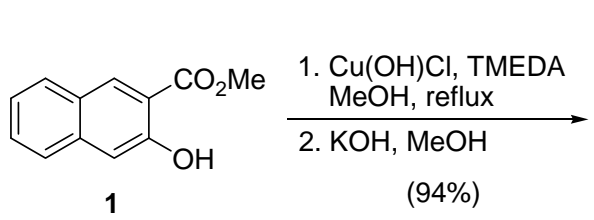

(94\%)<smiles>O=C(O)c1cc2ccccc2c(-c2c(O)c(C(=O)O)cc3ccccc23)c1O</smiles>

rac-2
1. Leu-OMe

2. Separation

3. aq. $\mathrm{HCl}$

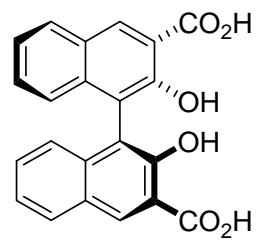

$\left(S_{a}\right)-2(22 \%, 98 \%$ ee $)$

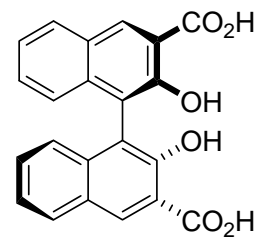

$\left(R_{\mathrm{a}}\right)-2(20 \%, 97 \%$ ee $)$<smiles>[X]Cc1cc2ccccc2c(-c2c(O)c(C[X])cc3ccccc23)c1O</smiles>

$\operatorname{rac}-3(\mathrm{X}=\mathrm{OH})$

$\operatorname{rac}-4\left(\mathrm{X}=\mathrm{NMe}_{2}\right)$

$\operatorname{rac}-5\left(\mathrm{X}=\mathrm{NMe}_{3} \mathrm{I}\right)$<smiles>CCC</smiles>

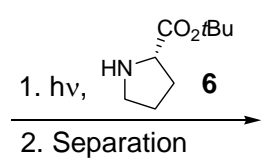

(45\%)<smiles>CCOC(=O)[C@@H]1CCCN1Cc1cc2ccccc2c(-c2c(CN3CCC[C@@H]3C(=O)OC(C)CC)cc3ccccc3c2O)c1O</smiles>

$\left(S_{a}\right)-8$ (>99\% de)<smiles>C=C1C=c2ccccc2=C(C2=c3ccccc3=CC(=C)C2=O)C1=O</smiles><smiles>CC1CC1C</smiles>

7

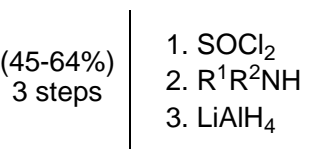

3. $\mathrm{LiAlH}_{4}$

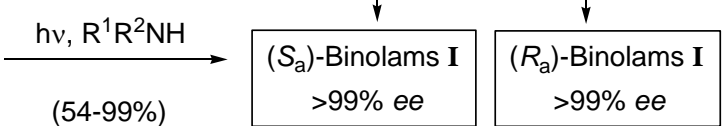<smiles>CCCCC1CCCN1C(=O)c1cc2ccccc2c(-c2c(O)c(C(=O)N3CCC[C@H]3C(=O)OCC)cc3ccccc23)c1O</smiles>

$\left(R_{\mathrm{a}}\right)-\mathbf{1 0}(66 \% d e)$ $\underset{\text { reflux }}{\stackrel{6 \mathrm{M} \mathrm{HCl}}{\longrightarrow}}$

(74\%)<smiles>O=C(O)c1cc2ccccc2c(-c2c(O)c(C(=O)O)cc3ccccc23)c1O</smiles>

$\left(R_{\mathrm{a}}\right)-2(97 \%$ ee $)$ $\underset{3 \text { steps }}{\stackrel{(\text { as above) }}{\longrightarrow}} \begin{gathered}\left(R_{\mathrm{a}}\right) \text {-Binolams I } \\ (97 \% \text { ee })\end{gathered}$

Scheme 1. Synthesis of Binolams I through optical resolution or by a diastereoselective manner.<smiles>CC(=O)c1cc2ccccc2cc1O</smiles>

1
$\mathrm{Cu}^{\prime}$ or $\mathrm{Cu}^{\mathrm{Il}}$ salts $(10 \mathrm{~mol} \%)$ chiral ligand (10 mol\%) $\mathrm{Cl}_{2} \mathrm{CH}_{2} \mathrm{CH}_{2} \mathrm{Cl}, 40^{\circ} \mathrm{C}$ (85-90\%)

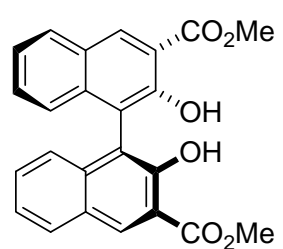

$\left(S_{\mathrm{a}}\right)-11$
Chiral ligands

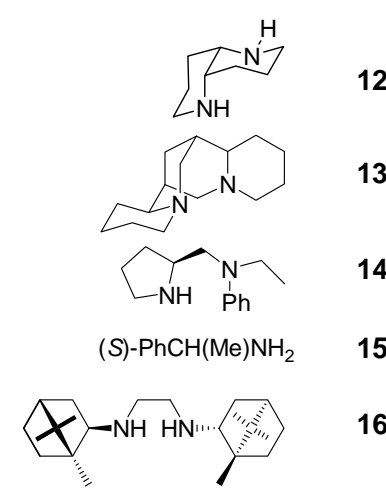<smiles>COC(=O)c1cc2ccccc2c(-c2c(O)c(C(C)=O)cc3ccccc23)c1O</smiles>

$\left(R_{\mathrm{a}}\right)-11$

91-93\% ee (ref. 14, 20)

$47 \%$ ee (ref. 22)

$78 \%$ ee (ref. 22)

$43 \%$ ee (ref. 21$)$

$65 \%$ ee (ref. 23) 


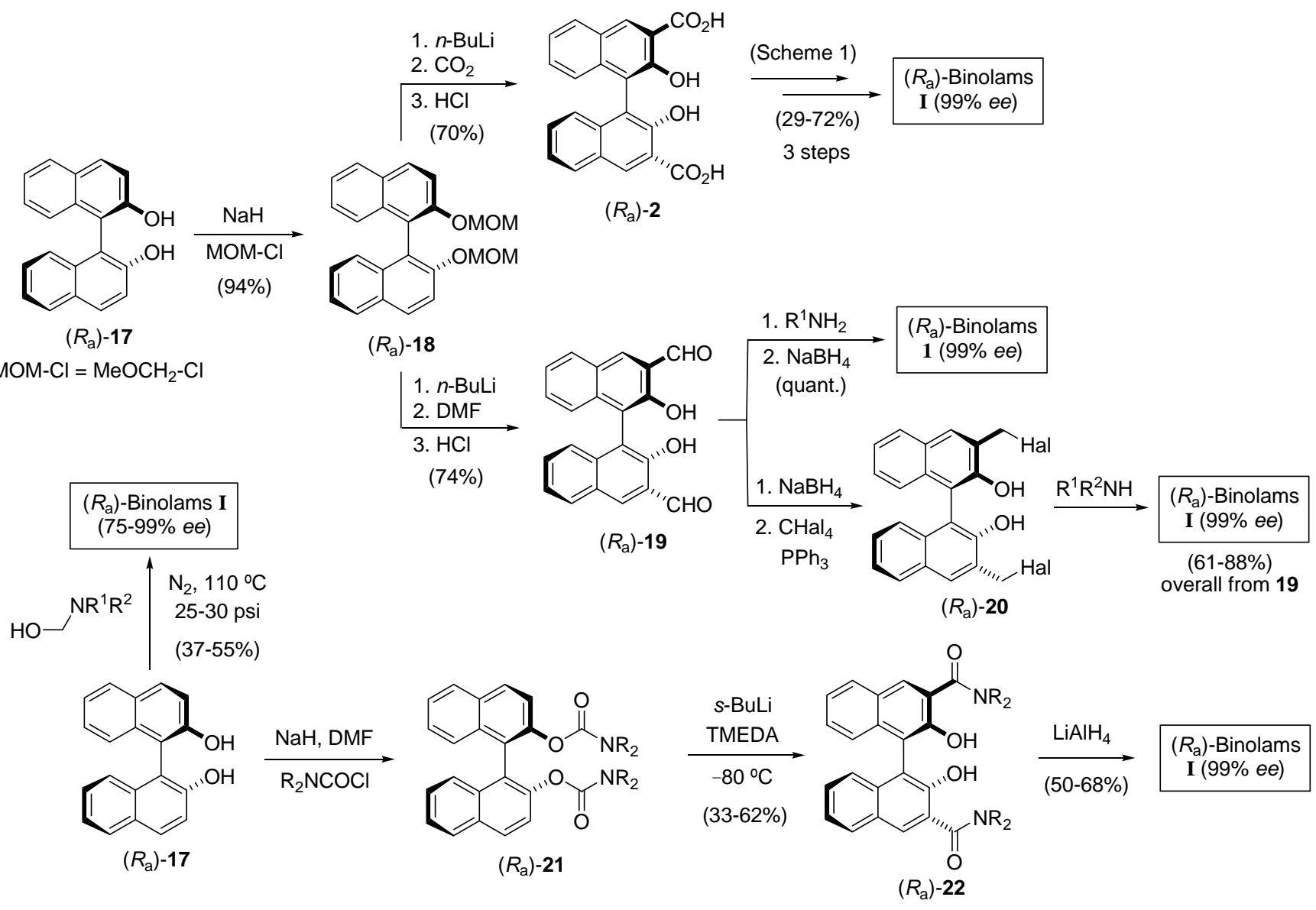

Scheme 3. Synthesis of Binolams I from chiral $\left(R_{\mathrm{a}}\right)$ - or $\left(S_{\mathrm{a}}\right)$-Binol 17.

a)
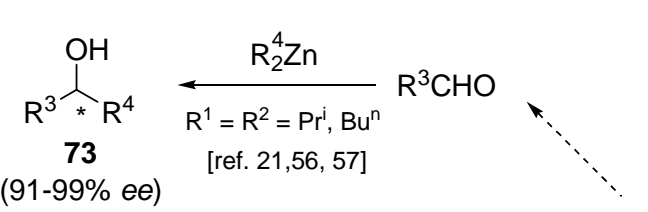

e)

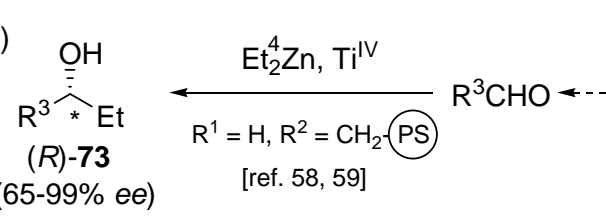

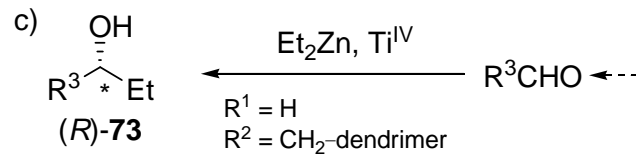<smiles>[R12]NC(=O)c1cc2ccccc2c(-c2c(O)c(C(=O)N[R12])cc3ccccc23)c1O</smiles>

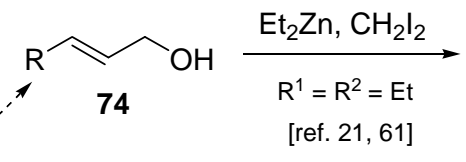<smiles>[R]C1CC1([Z5])[Z5]</smiles>

(67-94\% ee)

(46-72\% ee) [ref. 60]

d)

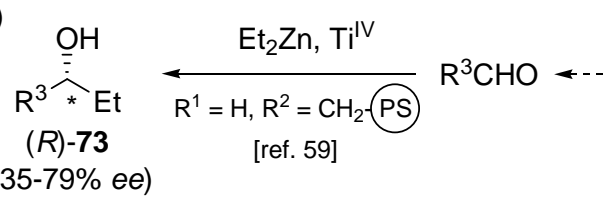<smiles></smiles><smiles>NC(C(=O)O)=C(O)c1ccccc1</smiles>
(up to $46 \%$ ee)

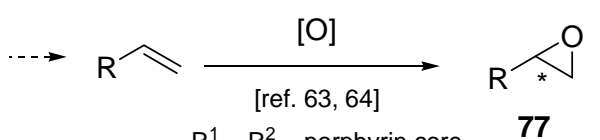

$\mathrm{R}^{1}=\mathrm{R}^{2}=$ porphyrin core

(up to $88 \%$ ee) 


\section{Layout 1:}

3,3'-Bis(dialkylaminomethyl)-1,1'binaphth-2ols (Binolams) have emerged both as organocatalysts and as appropriate chiral ligands for a large number of metal-catalyzed processes. As catalysts, the most valuable feature of Binolam-metal complexes is their dual capacity of activating both nucleophiles and electrophiles. The most successful transformations carried out with these type of bifunctional catalysts include, cyanation reactions onto aldehydes and ketones, enantioselective nucleophilic additions of enolate derivatives and organometallic compounds onto $\mathrm{C}=\mathrm{O}$ or $\mathrm{C}=\mathrm{N}$ double bonds.
Binolams

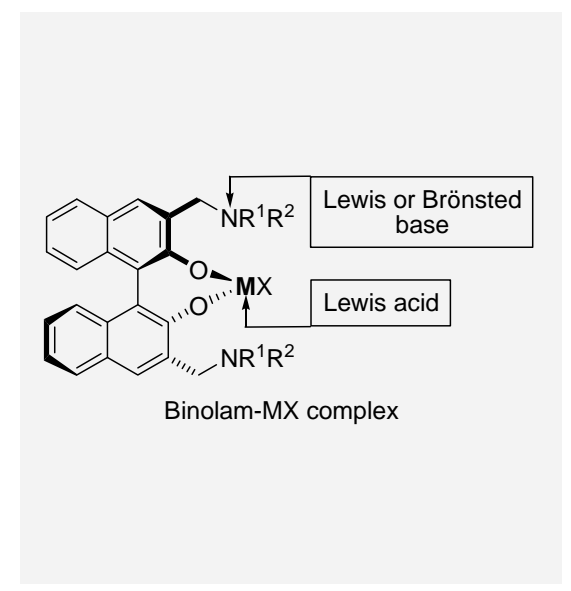

Carmen Nájera, José M. Sansano,* and José M. Saá ....... Page No. Page No.

Chiral 3,3'-Bis(aminomethyl)-1,1'-bi-2napththols (Binolams) in Asymmetric Catalysis

Keywords: Asymmetric catalysis / Binolam / organocatalysis / chiral complexes / bifunctional catalysts.

\section{References}

[1] Highlights in Bioorganic Chemistry, (Eds: C. Schmuck, H. Wennemers), Wiley-VCH, Weinheim, 2004.

[2] [2a] Compendium of Chiral Auxiliary Applications, (Ed: G. Roos), Academic Press, London, 2002; ${ }^{[2 b]}$ Stereoselective Synthesis, (Eds: G. Helmchen, R. W. Hoffmann, J. Mulzer, E. Schaumann), Houben-Weyl, Thieme, Stuttgart, 1996.

[3] Comprehensive Asymmetric Catalysis, (Eds: E. N. Jacobsen, A. Pfaltz, H. Yamamoto), Springer: Berlin, 1999; vol. I-III and 2004, supplements 1-2.

[4] ${ }^{[4 a]}$ Handbook of Reagents for Asymmetric Synthesis, (Ed: L. A. Paquette), Wiley, Chichester, 2003; ${ }^{[4 b]}$ Chiral Auxiliaries and Ligands in Asymmetric Synthesis, (Ed: J. Seyden-Penne), John Wiley \& Sons, Inc., New York, 1996.

[5] For reviews about bifunctional catalysis see: ${ }^{[5 a]}$ D. H. Paull, C. J. Abraham, M. T. Scerba, E. Alden-Danforth, T. Lectka, Acc. Chem. Res. 2008,41, 655-663. ${ }^{[5 b]}$ M. Shibasaki, M. Kanai, S. Matsunaga, Aldrichimica Acta 2006, 39, 31-39; ; ${ }^{[5]}$ M. Shibasaki, S. Matsunaga, Chem. Soc. Rev. 2006, 35, 269-279; ${ }^{[\mathrm{sd}]}$ T. Ikariya, K. Murata, R. Noyori, Org. Biomol. Chem. 2006, 4, 393-406; ${ }^{[5]}$ M. Kanai, N. Kato, E. Ichikawa, M. Shibasaki, Pure Appl. Chem. 2005, 77, 2047-2052; ${ }^{[5 f]}$ M. Kanai, N. Kato, E. Ichikawa, M. Shibasaki, Synlett 2005, 1491-1508; ; $\left.{ }^{[5]}\right]$ J.-M. Ma, D. Cahard, Angew. Chem. Int. Ed. 2004, 43, 4566-4583; ${ }^{[5 h]}$ M. Shibasaki, M. Kanai, K. Funabashi, Chem. Commun. 2002, 1989-1199; ${ }^{\left[{ }^{5 i}\right]}$ S. Matsunaga, T. Ohshima, M. Shibasaki, Adv. Synth. Catal. 2002, 344, 3-15; ${ }^{[5]]}$ H. Gröger, Chem. Eur. J. 2001, 7, 5246-5251; ${ }^{[5 \mathrm{k}]}$ G. J. Rowlands, Tetrahedron 2001, 57, $1865-1882$.

[6] J. K. Whitesell, Chem. Rev. 1989, 89, 1581-1590.

[7] PhD thesis of José González, Universitat de les Illes Balears, Palma de Mallorca, Spain.

[8] J. M. Brunel, Chem. Rev. 2005, 105, 857-897.

[9] B. E. Love, Curr. Org. Synth. 2006, 3, 169-185.

[10] D. J. Cram, R. G. Helgeson, S. C. Peacock, L. J. Kaplan, L. A. Domeier, P. Moreau, K. Koga, J. M. Mayer, Y. Chao, M. G. Siegel, D. H. Hoffman, G. Dotsevi, Y. Sogah, J. Org. Chem. 1978, 43, 1930-1946.

[11] P. R. Ashton, A. M. Heiss, D. Pasini, F. M. Raymo, A. N. Shipway, J. F. Stoddart, N. Spencer, Eur. J. Org. Chem. 1999, 995-1004;

${ }_{112]}^{[12 a]}$ E. V. Anslyn, J. Org. Chem. 2007, 72, 687-699; ${ }^{[12 b]}$ P. K. Baruah, R. Gonnade, P. R. Rajamohanan, H.-J. Hofmann, G. J. Sanjayan, J. Org. Chem. 2007, 72, 5077-5084; ${ }^{\left[{ }^{12 c]}\right.}$ M. Capó, J. González, H. Adams, Eur. J. Org. Chem. 2004, 3405-3408; ${ }^{[12]}$ M. Capó, J. M. Saá, A. Álvarez, Chem. Commun. 2002, 1982-1983.

[13] ${ }^{[13 a]}$ J. Heo, C. A. Mirkin, Angew. Chem. Int. Ed. 2006, 45, 941-944; ${ }^{[13 b]}$ J. Kikuchi, Z.-Y. Zhang, T. Miyahima, Y. Murakami, Chem. Lett. 1994, 1701-1704; ${ }^{[13 c]}$ Y. Murakami, Y. Hisaeda, T. Miyajima, J. Kikuchi, Chem. Lett. 1993, 2093-2096; ${ }^{[13 d]}$ Y. Murakami, Y. Hisaeda, T. Miyajima, H. Sakata, J. Kikuchi, Chem. Lett. 1993, 645-648.

${ }^{[14]}{ }^{[14 a]}$ F. Doria, S. N. Richter, M. Nadai, S. Colloredo-Mels, M. Mella, M. Palumbo, M. Freccero, J. Med. Chem. 2007, 50, 6570-6579; ${ }^{[14 b]}$ S. ColloredoMels, F. Doria, D. Verga, M. Freccero, J. Org. Chem. 2006, 71, 3889-3895; ${ }^{[14 c]}$ S. N. Richter, S. Maggi, S. Colloredo-Mels, M. Palumbo, M. Freccero, J. Am. Chem. Soc. 2004, 126, 13973-13979.

[15] C. A. Mulrooney, X. Li, E. S. DiVirgilio, M. C. Kozloswski, J. Am. Chem. Soc. 2003, 125, 6856-6857.

${ }^{[16]}{ }^{[16 a]}$ Z.-B. Li, J. Lin, M. Sabat, M. Hyacinth, L. Pu, J. Org. Chem. 2007, 72, 4905-4916; ${ }^{\left[{ }^{[16 b]}\right.}$ Z.-B. Li, L. Pu, J. Mater. Chem. 2005, 15, 2860-2864; ${ }^{[16 c]}$ Z.-B. Li, J: Lin, Y.-C. Qin, L. Pu, Org. Lett. 2005, 7, 3441-3444; ${ }^{[16 d]}$ Z.-B. Li, J. Lin, L. Pu, Angew. Chem. Int. Ed. 2005, 44, 1690-1693; ${ }^{[16]}$ L. lin, A. R. Rajaram, L. Pu, Tetrahedron 2004, 60, 11277-1281; ${ }^{[16 f]}$ J. Lin, H.-C. Zhang, L. Pu, Tetrahedron Lett. 2004, 45, 103-106; ${ }^{[16 g]}$ J. Zhao, T. M. Fyles, T. D. James, Angew. Chem. Int. Ed. 2004, 43, 3461-3464; ${ }^{16 h]}$ Z.-B. Li, j. Lin, H.-C. Zhang, M. Sabat, M. Hyacinth, L. Pu, J. Org. Chem. 2004, 69, 6284-6293; ${ }^{[16 i]}$ J. Lin, H.-C. Zhang, L. Pu, Org. Lett. 2002, 4, 3297-3300; ${ }^{[16 j]}$ C. W. Gray, Jr., T. A. Houston, J. Org. Chem. 2002, 67, 5426$5428 ;{ }^{[16 k]}$ T. D. James, K. R. A. S. Sansanayake, S. Shinkai, Nature (London) 1995, 374, 346-347.

[17] ${ }^{[17 a]}$ J. Brussee, J. L. G. Groenendijk, J. M. Koppele, A. C. A. Jansen, Tetrahedron 1985, 41, 3313-3319; ${ }^{[176]}$ B. Feringa, H. Wynberg, Tetrahedron Lett. 1977, 4447-4450. The iron(III) coupling has been also reported: ${ }^{[17]}$ B. E. Love, R. A. Bills, Synth. Commun. 2002, 32, $2067-2073$.

[18] B. M. Trost, D. R. Fandrick, Aldrichim. Acta 2007, 40, 59-72.

[19] Z. Xin, C. Da, S. Dong, D. Liu, J. Wei, R. Wang, Tetrahedron: Asymmetry 2002, 13, 1937-1940. 
[20] ${ }^{[20 a]}$ X. Xie, P.-W. Phuan, M. C. Kozlowski, Angew. Chem. Int. Ed. 2003, 42, 2168-2170; ${ }^{[20 b]}$ X. Li, B. Hewgley, C. A. Mulrooney, J. Yang, M. C. Kozlowski, J. Org. Chem. 2003, 68, 5500-5511; ${ }^{[20 c]}$ M. C. Kozlowski, X. Li, P. J. Carrol, Z. Xu, Organometallics 2002, 21, 4513-4522; ${ }^{[20 d]}$ X. Li, J. Yang, M. C. Kozlowski, Org. Lett. 2001, 3, 1137-1140.

[21] M. Smrcina, J. Polakova, S. Vyscocil, P. Kocovsky, J. Org. Chem. 1993, 58, 4534-4538.

${ }^{[22]}{ }^{[22 a]}$ M. Nakajima, I. Miyoshi, K. Kanayama, S. Hashimoto, M. Noji, K. Koga, J. Org. Chem. 1999, 64, 2264-2271; ${ }^{[22 b]}$ M. Nakajima, I. Miyoshi, K. Kanayama, S. Hashimoto, Tetrahedron Lett.. 1995, 36, 9519-9520.

[23] A. Caselli, G. B. Giovenzana, G. Palmisano, M. Sisti, T. Pilati, Tetrahedron: Asymmetry 2003, 14, 1451-1454

[24] H. Kitajima, K. Ito, Y. Aoki, T. Katsuki, Bull. Chem. Soc. Jpn. 1997, 70, 207-217.

[25] S. Arai, K. Tokumaru, T. Aoyama, Chem. Pharm. Bull. 2004, 52, 646-648.

[26] Y.-C. Qin, L. Pu, Org. Lett. 2005, 7, 2381-2383.

[27] M. R. Dennis, S. Woodward, J. Chem. Soc. Perkin Trans. 1 1998, 1081-1085.

[28] Y.-C. Qin, L. Liu, M. Sabat, L. Pu, Tetrahedron 2006, 62, 9335-9348.

[29] Y.-C. Qin, L. Pu, Angew. Chem. Int. Ed. 2006, 45, 273-277.

[30] H. Kitajima, T. Katsuki, Synlett 1997, 568-570.

[31] H. Kitajima, K. Ito, T. Katsuki, Tetrahedron 1997, 53, 17015-17028.

[32] For general applications and asymmetric synthesis of cyanohydrins and their derivatives, see: ${ }^{[32 a]}$ A. Baeza, C. Nájera, J. M. Sansano, Pure Appl. Chem. 2007, 79, 213-221; ${ }^{[32 b]}$ F. Effenberger, S. Foerster, C. Kobler, in: Biocatalysis in the Pharmaceutical and Biotechnology Industries. Ed. by Patel R. N. CRC Press, Boca Ratón, 2007, chp. 28, 677-698; ${ }^{[32 c]}$ F.-X. Chen, X. Feng, Curr. Org. Synth. 2006, 3, 77-97; ${ }^{[32 d]}$ T. R. J. Achard, L. A. Clutterbuck, M. North Synlett 2005, 1828-1847; ${ }^{[32 e]}$ M. Kanai, N. Nato, E. Ichikawa, M. Shibasaki, Synlett 2005, $892-899 ;{ }^{[32 f]}$ F. X. Chen, X. M. Feng, Synlett 2005, 892-899; ${ }^{[32 g]}$ M. North, Ed. "Synthesis and applications of non-racemic cyanohydrins and $\alpha$-amino acids" Tetrahedron 2004, 60, 10371-10568; ${ }^{[32 h]}$ J.-M. Brunel, I. P. Holmes, Angew. Chem., Int. Ed. 2004, 116, 2810-2837; ${ }^{[32 i]}$ M. North, Tetrahedron: Asymmetry 2003, 14, $147-176 ;{ }^{[32 j]}$ P. Vachal, E. N. Jacobsen, in Comprehensive Asymmetric Catalysis. E. N. Jacobsen, A. Pfaltz, H. Yamamoto, Eds. Supplement 1, pp. $117-129 ;{ }^{[32 k]}$ R. J. H. Gregory Chem. Rev. 1999, 99, 3649-3682; ${ }^{[25 l]}$ F. Effenberger, Angew. Chem., Int. Ed. 1994, 106, 1609-1619; ${ }^{[32 \mathrm{~m}]}$ M. North, Synlett 1993, 807-820.

[33] D. Sawada, M. Kanai, M. Shibasaki, J. Am. Chem. Soc. 2000, 43, 10521-10532.

[34] J. Casas, C. Nájera, J. M. Sansano, J. M. Saá, Org. Lett. 2002, 4, 2589-2592.

[35] J. Casas, C. Nájera, J. M. Sansano, J. M. Saá, Tetrahedron 2004, 60, 10487-10496.

[36] E. J. Corey, T. W. Lee, Chem. Commun. 2001, 1321-1329.

[37] F. Yang, S. Wei, C. A. Chen, P. Xi, L. Yang, J. Lan, H.-M. Gau, J. You, Chem. Eur. J. 2008, 14, 2223-2231.

[38] J. Casas, A. Baeza, J. M. Sansano, C. Nájera, J. M. Saá, Tetrahedron: Asymmetry 2003, 14, 197-200.

[39] A. Baeza, J. Casas, C. Nájera, J. M. Sansano, J. M. Saá, Eur. J. Org. Chem. 2006, 14, 1949-1958.

[40] S. Gou, X. Liu, X. Zhou, X. Feng, Tetrahedron 2007, 63, 7935-7941.

[41] A. Baeza, C. Nájera, J. M. Sansano, J. M. Saá, Tetrahedron: Asymmetry 2005, 16, 2385-2389.

[42] A. Baeza, J. Casas, C. Nájera, J. M. Sansano, J. M. Saá, Angew. Chem. Int. Ed. 2003, 42, 3143-3146.

[43] A. Baeza, C. Nájera, J. M. Sansano, J. M. Saá, Chem. Eur. J. 2005, 11, 3849-3862.

[44] A. Baeza, J. Casas, C. Nájera, J. M. Sansano, J. Org. Chem. 2006, 71 3837-3848.

[45] A. Baeza, C. Nájera, J. M. Sansano, Eur. J. Org. Chem. 2007, 1101-1112.

[46] D. V. Johnson, H. Griengl, Tetrahedron 1997, 53, 617-624.

[47] $\mathrm{PhD}$ thesis of Alejandro Baeza, Universidad de Alicante, Spain.

[48] Z. Hou, J. Wang, X. Liu, X. Feng, Chem. Eur. J. 2008, 14, 4484-4486.

[49] S. Gou, X. Zhou, J. Wang, X. Liu, X. Feng, Tetrahedron 2008, 64, 2864-2870.

[50] G. Masson, C. Housseman, J. Zhu, Angew. Chem. Int. Ed. 2007, 46, 4614-4628.

[51] K. Matsui, S. Takizawa, H. Sasai, J. Am. Chem. Soc. 2005, 127, 3680-3681.

[52] K. Matsui, K. Tanaka, A. Horii, S. Takizawa, H. Sasai, Tetrahedron: Asymmetry 2006, 17, 578-583.

[53] K. Matsui, S. Takizawa, H. Sasai, Synlett 2006, 761-765.

$[54]{ }^{[54 a]}$ T. Vilaivan, W. Bhanthumnavin, Y. Sritana-Anant, Curr. Org. Chem. 2005, 9, 1315-1392; ${ }^{[54 b]}$ H. Gröger, Chem. Rev. 2003, 103, 2795-2827. ${ }^{\left[{ }^{44 c}\right]}$ B. Westermann, Angew. Chem. Int. Ed. 2003, 42, 151-153. ${ }^{[54 \mathrm{~d}]}$ F. A. Luzzio Tetrahedron 2001, 57, 915-945. ${ }^{[54 \mathrm{c}]}$ N. Ono, The Nitro Group in Orgnic Synthesis, Wiley-VCH, Weinheim, 2001, chp. 3, pp 30-68.

[55] J. M. Saá, F. Tur, J. González, M. Vega, Tetrahedron: Asymmetry 2006, 17, 99-106.

[56] J.M. Saá, F. Tur, J. González, Chirality 2008, in press.

[57] F. Tur, J. M. Saá, Org. Lett. 2007, 9, 5079-5082.

[58] A. M. DeBerardinis, M. Turlington, L. Pu, Org. Lett. 2008, 10, 2709-2712.

[59] Y.-N. Lu, Q.-S. Guo, F.-Y. Jiang, J.-S. Li, Tetrahedron: Asymmetry 2006, 17, 1842-1845.

[60] C. Nájera, J. M. Sansano, Chem Rev. 2007, 107, 4584-4671.

[61] J. Casas, C. Nájera, J. M. Sansano, J. González, J. M. Saá, M. Vega, Tetrahedron: Asymmetry 2001, 12, 699-702.

[62] T. Nagataki, Y. Tachi, S. Itoh, J. Mol. Catal. A: Chem. 2005, 225, 103-109.

[63] H. Li, C.-S. Da, Y.-H. Xiao, X. Li, Y.-N. Su, J. Org. Chem. 2008, 73, 7398-7401.

[64] H. Kitahima, K. Ito, T. Katsuki, Chem. Lett. 1996, 343-344.

[65] K. Ito, Y. Tomita, T. Katsuki, Tetrahedron Lett. 2005, 46, 6083-6086.

[66] X.-W. Yang, J.-H. Sheng, C.-S. Da, H.-S. Wang, W. Su, R. Wang, A. S. C. Chan, J. Org. Chem. 2000, 65, 295-296.

[67] X. Yang, W. Su, D. Liu, H. Wang, J. Shen, C. Da, R. Wang, A. C. S. Chan, Tetrahedron 2000, 56, 3511-3516.

[68] G.-H. Liu, Q.-H. Fan, X.-Q. Yang, X.-M. Chen, Arkivoc 2003, ii, 123-132.

[69] H. Kitajima, Y. Aoki, K. Ito, T. Katsuki, Chem. Lett. 1995, 1113-1114.

[70] Y. Murakami, J.-I. Kikuchi, T. Miyahima, Y. Hisaeda, Chem. Lett. 1994, 55-58.

[71] E. Rose, M. Quelquejeu, R. P. Pandian, A. Lecas-Nawrocka, A. Vilar, G. Ricart, J. P. Collman, Z. Wang, A. Straumanis, Polyhedron 2000, 19, 581586.

[72] W. Adam, S. Prikhodovski, K. J. Roschmann, C. R. Saha-Möller, Tetrahedron: Asymmetry 2001, 12, 2677-2681.

[73] T. P. Yoon, E. N. Jacobsen, Science 2003, 299, 1691-1693. 